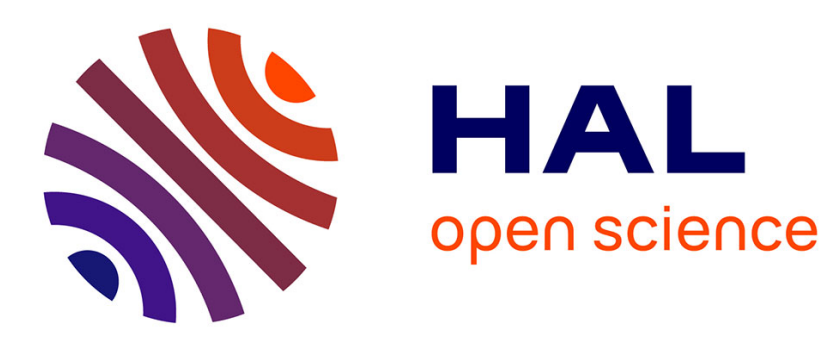

\title{
Circularly permuted fluorogenic proteins for the design of modular biosensors
}

\author{
Alison G Tebo, Frederico M Pimenta, Martha Zoumpoulaki, Carlos Kikuti, \\ Helena Sirkia, Marie-Aude Plamont, Anne Houdusse, Arnaud Gautier
}

\section{- To cite this version:}

Alison G Tebo, Frederico M Pimenta, Martha Zoumpoulaki, Carlos Kikuti, Helena Sirkia, et al.. Circularly permuted fluorogenic proteins for the design of modular biosensors. ACS Chemical Biology, 2018, 13 (9), pp.2392 - 2397. 10.1021/acschembio.8b00417 . hal-01909679

\section{HAL Id: hal-01909679 \\ https://hal.sorbonne-universite.fr/hal-01909679}

Submitted on 31 Oct 2018

HAL is a multi-disciplinary open access archive for the deposit and dissemination of scientific research documents, whether they are published or not. The documents may come from teaching and research institutions in France or abroad, or from public or private research centers.
L'archive ouverte pluridisciplinaire HAL, est destinée au dépôt et à la diffusion de documents scientifiques de niveau recherche, publiés ou non, émanant des établissements d'enseignement et de recherche français ou étrangers, des laboratoires publics ou privés. 


\section{Circularly permuted fluorogenic proteins for the design of modular biosensors}

Alison G. Tebo ${ }^{1, \#, ~ F r e d e r i c o ~ M . ~ P i m e n t a ~}{ }^{1, \#}$, Martha Zoumpoulaki ${ }^{1}$, Carlos Kikuti ${ }^{2}$, Helena Sirkia ${ }^{2}$, Marie-Aude Plamont ${ }^{1}$, Anne Houdusse ${ }^{2} \&$ Arnaud Gautier $^{1, *}$

${ }^{1}$ PASTEUR, Département de Chimie, École Normale Supérieure, PSL University, Sorbonne Université, CNRS, 75005 Paris, France.

${ }^{2}$ Structural Motility, Institut Curie, PSL Research University, CNRS, UMR 144, F-75005 Paris, France.

\#Equal contributions.

*Correspondence should be addressed to: arnaud.gautier@ens.fr 


\section{ABSTRACT}

Fluorescent reporters are essential components for the design of optical biosensors able to image intracellular analytes in living cells. Herein, we describe the development of circularly permuted variants of Fluorescence-Activating and absorption-Shifting Tag (FAST) and demonstrate their potential as reporting module in biosensors. Circularly permutated FAST (cpFAST) variants allow one to condition the binding and activation of a fluorogenic ligand (and thus fluorescence) to analyte recognition by coupling them with analyte-binding domains. We demonstrated their use for biosensor design by generating multicolor plug-and-play fluorogenic biosensors for imaging the intracellular levels of $\mathrm{Ca}^{2+}$ in living mammalian cells in real-time. 
Cells respond to external and internal stimuli by a series of biochemical events that are tightly controlled in space and time. These downstream processes consist of interactions between macromolecules as well as between macromolecules and analytes. Detecting these interactions involves coupling a measurable output to a nanometer-scale molecular recognition event, typically by linking a reporting module to a sensing domain that responds to an input by undergoing a conformational change. Fluorescent proteins (FP) such as the green fluorescent protein (GFP) and its variants have been essential in the development of genetically encoded optical biosensors. FP-based biosensors typically function either by Förster resonance energy transfer (FRET), in which an analyte-binding domain is flanked with two FPs acting as donor and acceptor for FRET studies, or by fluorescence intensity change, in which conformational changes induced by analyte binding change the local environment of the chromophore of circularly permuted FPs. ${ }^{1-4}$

Chemical-genetic fluorogenic reporters provide an attractive alternative to FPs as they display many of the same advantages, while capitalizing on the specific interaction of a fluorogenic chromophore (so-called fluorogen) with its cognate genetically encoded receptor in order to generate fluorescence. ${ }^{5-7}$ Fluorogens are chromophores that display no fluorescence until they interact with their cognate tag, resulting in systems with low background signal and little to no maturation time. The modular nature of these reporters opens exciting prospects for the design of genetically encoded biosensors in which fluorogen binding, and thus fluorescence, is conditioned to the recognition of a given analyte. An elegant illustration of this principle was obtained using Spinach, an RNA aptamer that 
binds analogs of the GFP chromophore ${ }^{8}$. The coupling of metabolite-specific RNA aptamers to Spinach led to biosensors in which metabolite binding promote Spinach fluorescence $^{9,10}$.

To validate this approach with protein-based fluorogenic systems (Figure 1A), which have the advantages of being genetically targetable to any subcellular localization and in principle implementable in all model cells and organisms, we evaluated the use of the Fluorescence-Activating and absorption-Shifting Tag (FAST) ${ }^{11}$, a variant of the $14 \mathrm{kDa}$ photoactive yellow protein (PYP) evolved to bind and activate (through conformational locking) the fluorescence of various hydroxybenzylidene rhodanine (HBR) derivatives $^{11,12}$. As fluorogen binding affinity depends on the protein structure, we anticipated that conformational change would affect fluorogen binding and thus fluorescence.

To maximize conformational coupling and facilitate insertion of FAST as reporting module into multidomain biosensors, we circularly permuted the protein. Circular permutation is a method used both in the laboratory and by nature whereby the amino acid sequence is altered such that the $\mathrm{N}$ and $\mathrm{C}$ termini are close in space but the protein retains the same (or similar) 3D structure (and hence function). Relocating the $\mathrm{N}$ - and $\mathrm{C}$ - termini within the structure of a protein to be spatially close has proved to be effective in increasing conformational sensitivity. This technique has been successfully used in the development of most intensiometric FP-based biosensors ${ }^{13-15}$. We hypothesized that FAST would tolerate circular permutation in much the same way as its parent protein, PYP. ${ }^{16}$ Furthermore, we 
reasoned that such a development could provide a strategy to create FAST-based biosensors by co-opting previously well-characterized sensor designs. For instance, calcium sensors composed of a circularly permuted FP and a calcium-binding motif comprised of calmodulin and M13 have been extensively explored. ${ }^{13,14}$ In these sensors, the calciumbinding moieties calmodulin and M13 are appended to the $N$ and $C$ termini of the circularly permuted fluorescent protein and binding of $\mathrm{Ca}^{2+}$ results in the formation of the calmodulin and M13 ternary complex, which in turn induces a conformational change in FP, and results in higher fluorescence. This design, which has been implemented with Aequorea GFP or its variants, has not yet been successfully adapted to other fluorescent reporting modules. Herein, we describe the development of a series of circularly permuted FAST (cpFAST) variants with fluorogen affinities spanning an order of magnitude and illustrate using calcium sensors as a proof of principle that these cpFASTs can replace classic FPs for the design of intensiometric biosensors.

We designed seven circularly permuted FAST (cPFAST) variants by linking the original termini with peptide linkers of various lengths, and created new $\mathrm{N}$ - and $\mathrm{C}$ - termini at positions 115 and 114 , respectively, as previously reported for circularly permuted PYP. ${ }^{16}$ All cpFASTs showed good expression in E. coli (Figure S1) and formed green-yellow fluorescent complexes with 4-hydroxy-3-methylbenzylidene rhodanine (HMBR), indicating that the circular permutation did not perturb the three-dimensional topology and function of FAST. Absorption and emission wavelengths, fluorescence quantum yields, and absorption coefficients were nearly identical to those of non-permuted FAST (Table 1). Interestingly, we observed that the shorter the linker inserted within cpFAST, the lower 
the affinity for HMBR (Table 1 and Figure S2). This trend may result from shorter linkers introducing a physical constraint in the three-dimensional structure of the protein, thus inducing a lower binding affinity. All cpFAST were shown to activate HMBR fluorescence in live cells (Figure S3).

To validate the use of our cpFASTs for biosensor design, we created a sensor able to selectively detect $\mathrm{Ca}^{2+}$ by taking advantage of the $\mathrm{Ca}^{2+}$-dependent interaction of calmodulin (CaM) and the $\mathrm{Ca}^{2+}-\mathrm{CaM}$ interacting peptide $\mathrm{M} 13$, which has been successfully used in the past to generate genetically encoded FP-based calcium indicators (Figure S4) $)^{13,14,17} \cdot \mathrm{Ca}^{2+}$ is a highly versatile secondary messenger that regulates many different cellular functions over a wide temporal range ${ }^{18}$. The concentration $\mathrm{Ca}^{2+}$ at resting state and the amplitude of the concentration change can vary significantly as a function of the intracellular localization and the cell type, therefore $\mathrm{Ca}^{2+}$ biosensors with various dissociation constants (ideally from $\mathrm{nM}$ to $\mathrm{mM}$ ) are required to fully address the physiological role of $\mathrm{Ca}^{2+}$ signaling. Because of the dynamic and transient nature of calcium signaling, $\mathrm{Ca}^{2+}$ was an ideal model analyte for us to validate the use of cpFASTs for the design of dynamic fluorogenic biosensors. We connected the N-terminus of cpFASTs to the M13 peptide and their C-terminus to calmodulin (CaM). The corresponding sensors were expressed in E. coli with high yields (Figure S5), allowing full in vitro characterization.

For all sensors, the presence of $\mathrm{Ca}^{2+}$ increased $\mathrm{HMBR}$ binding affinity (Figures 1B and S6 and Table 2), demonstrating that $\mathrm{Ca}^{2+}$ promoted fluorogen binding. We observed that 
the shorter the linker used within the cpFAST, the larger the $\mathrm{Ca}^{2+}$-induced increase in affinity. In agreement with the circular permutation providing conformational sensitivity, most cpFAST-based sensors displayed a larger $\mathrm{Ca}^{2+}$-induced change in fluorogen affinity than a sensor in which the original FAST was inserted (Table 2).

An important feature of FAST is the ability to change its color from green-yellow to orangered by using 4-hydroxy-3,5-dimethoxybenzylidene rhodanine (HBR-3,5-DOM) instead of $\mathrm{HMBR}^{12}$. We therefore tested HBR-3,5-DOM with the cpFAST-based sensors. $\mathrm{Ca}^{2+}$-dependent increases in fluorogen affinity were also observed in that case (Figures 1C and S7 and Table 2), demonstrating that the color of the sensors could be tuned at will from green-yellow to orange-red by choosing the appropriate fluorogen. This unprecedented feature provides an experimental versatility not encountered with FP-based biosensors, for which changing the color has required significant reengineering efforts ${ }^{14}$. With FASTbased sensors, sensor optimization is effectively decoupled from color choice, allowing plug-an-play color change.

In intensiometric fluorogen-based sensors, the dynamic range of the sensors is dependent on the conditions of the experiment, notably the fluorogen concentration used (See SI Text 1 and Figure S8). To evaluate the dynamic range of our sensor, we measured the fluorescence fold increase for cpFAST2-based sensor in a range of fluorogen concentrations sampling a large range of conditions and expected fluorescence fold increases (Figure 1D-G). The observed fluorescence fold increase was slightly higher ( 
1.2) than predicted based solely on the change in fraction of sensor:fluorogen complex, suggesting that the brightness of the sensor was also influenced by $\mathrm{Ca}^{2+}$, which we attributed to an increased rigidity of the sensor in the presence of $\mathrm{Ca}^{2+}$. Similar results were obtained with sensors based on other cpFASTs (Figure S9).

Next, we determined the $\mathrm{Ca}^{2+}$ affinity of our sensors. We fixed the concentration of fluorogen so that to maximize the change in fraction of sensor:fluorogen complex (see SI Text 1). The tested sensors displayed tight $\mathrm{Ca}^{2+}$ binding with dissociation constants $\left(K_{\mathrm{D}, \mathrm{Ca}}\right)$ of about 60 to $100 \mathrm{nM}$, in good agreement with that of the CaM and M13 fusion protein linked with two amino acid linkers previously reported $\left(K_{\mathrm{D}, \mathrm{Ca}} \text { of } 80 \mathrm{nM}\right)^{19,20}$, and Hill coefficients $\left(n_{H}\right)$ of about 3 in agreement with cooperative $\mathrm{Ca}^{2+}$ binding to CaM (Figures $1 \mathrm{H}, \mathrm{I}, \mathrm{S10}-\mathrm{S} 13$ and Table 2). Neither the fluorogen used (HMBR or HBR-3,5-DOM) nor the cpFAST chosen had a significant influence on the affinity for $\mathrm{Ca}^{2+}$. Furthermore, we examined the dependence of $K_{\mathrm{D}, \mathrm{Ca}}$ on fluorogen concentration for the sensor based on cpFAST2. We found that $\mathrm{Ca}^{2+}$ affinity is only slightly dependent on the fluorogen concentration (Figure S10 and S11), indicating that experimental conditions may be tuned at will without affecting the basics of sensor function. The absence of strong dependence of the $\mathrm{Ca}^{2+}$ affinity on the fluorogen concentration in this case is linked to the cooperative binding of $\mathrm{Ca}^{2+}$. With their high $\mathrm{Ca}^{2+}$ affinity, our cpFAST-based biosensors can allow the detection of subtle changes in $\mathrm{Ca}^{2+}$ concentration and complement the current suite of widely used single-FP-based $\mathrm{Ca}^{2+}$ indicators ${ }^{21}$. 
We next evaluated the function of our cpFAST-based $\mathrm{Ca}^{2+}$ sensors in living cells. When the sensors were expressed in HeLa cells and labeled with HMBR or HBR-3,5-DOM, the fluorescence was uniformly distributed in cells (Figure 2). This observation was in agreement with the sensors being small $(33 \mathrm{kDa})$, monomeric proteins as confirmed by sizeexclusion chromatography coupled to multiangle light scattering (Figure S14). Treatment with histamine, which triggers $\mathrm{Ca}^{2+}$ release from the endoplasmic reticulum to the cytoplasm, induced a significant increase of fluorescence (2 to 3-fold), in accordance with an increase of cytosolic free $\mathrm{Ca}^{2+}$ (Figure 2, and movies S1-S3). This initial peak was followed by oscillations and eventually desensitization (Figure 2 and movies S1-S3). Our sensors did not display the striking oscillations reported with recently, highly-optimized sensors very likely because of their high affinity for $\mathrm{Ca}^{2+}$. However, the observed response was in good agreement with the known behavior of HeLa cells to histamine stimulation ${ }^{13,14,20,21}$, demonstrating our ability to image $\mathrm{Ca}^{2+}$ levels in living cells in real-time.

In this study, we report the design of functional circularly permuted FAST variants (cpFAST). We demonstrate using $\mathrm{Ca}^{2+}$ sensors as a proof-of-principle that cpFASTs can be an alternative to FPs as reporting module in biosensors. In cpFAST-based sensors, the intensiometric response results from conditioning fluorogen binding (and thus fluorescence) to the recognition of an intracellular analyte. We could generate functional $\mathrm{Ca}^{2+}$ biosensors with minimal engineering efforts. The successful design of FP-based sensors of the GCaMP family - made of circular permuted GFP flanked with CaM and M13 results from the serendipitous specific interaction between CaM and GFP in presence of $\mathrm{Ca}^{2+}$ that strongly affects GFP conformation and photophysical properties ${ }^{22}$. Engineering 
efforts to implement this design to generate genetically encoded calcium indicators with fluorescent reporter modules other than FPs have not been successful so far..$^{23}$ In addition, extension of this serendipity-based design principle to analytes other than $\mathrm{Ca}^{2+}$ has turned out to be highly challenging. ${ }^{15,24-27}$ FAST-based $\mathrm{Ca}^{2+}$ sensors display $\mathrm{Ca}^{2+}$-dependent fluorescence without the need for a specific direct interaction between FAST and the $\mathrm{Ca}^{2+}$ sensing domains, which should thus facilitate the extension of this design principle to other analytes using various sensing modules. The ability to change the color by changing the fluorogen used allows the design of biosensors with various spectral properties without the need for reengineering, providing an unprecedented experimental versatility for multicolor imaging.

Although conformationally coupling of FAST and the sensing unit allows one to condition fluorogen binding to analyte recognition, it also makes the dynamic range of the sensor and the affinity for the analyte dependent on the fluorogen concentration. Consequently, the fluorogen concentration is a control parameter that must be chosen with care to optimize measurements with the sensors. Despite this, the use of FAST for sensor design opens exciting perspectives. Its robustness and tolerance to insertions make FAST a particularly interesting scaffold for sensor design at once taking advantage of its relatively small size and the ability to change its color at-will. The use of cpFASTs could prove useful in the screening of new sensing modules for which current development is stifled by intrinsic limitations of FPs such as maturation time, tendency to oligomerize, and oxygen sensitivity. The simplicity and tractability of such an approach should allow the design of new plug-and-play biosensors for imaging in real-time analytes, endogenous biomolecules and cellular processes for which no systems currently exist. 


\section{SUPPORTING INFORMATION}

The supporting information contains Movies S1-S3, SI Text 1, Figures S1-S14 and Materials and Methods.

\section{ACKNOWLEDGEMENTS}

This work was supported by the European Research Council (ERC-2016-CoG-724705 FLUOSWITCH), the Agence National de la Recherche (ANR-14-CE09-0002- 01), France Biolmaging (ANR-10-INBS-04), the Equipex Morphoscope 2 (ANR-11-EQPX-0029) and the program «Investissements d'Avenir » launched by the French Government and implemented by ANR (ANR-10-IDEX-0001-02 PSL, project Superline).

\section{NOTES}

The authors declare the following competing financial interest: A.G. is co-founder and holds equity in Twinkle Bioscience, a company commercializing the FAST technology. 
Table 1. Physico-chemical properties of the circularly permuted FAST (cpFAST) variants bound to HMBR. Abbreviations are as follows: $\lambda_{\text {abs, }}$, wavelength of maximal absorption; $\lambda_{\mathrm{em}}$, wavelength of maximal emission; $\varepsilon$, molar absorption coefficient at $\lambda_{\text {abs; }}$; $\phi$, fluorescence quantum yield; $K_{D}$, thermodynamic dissociation constant.

\begin{tabular}{ccccccc}
\hline Variant & $\begin{array}{c}\text { Linker size } \\
(\text { a.a. })\end{array}$ & $\begin{array}{c}\lambda \text { abs } \\
(\mathrm{nm})\end{array}$ & $\begin{array}{c}\lambda_{\mathrm{em}} \\
(\mathrm{nm})\end{array}$ & $\begin{array}{c}\varepsilon \\
\left(\mathrm{mM}^{-1} \mathrm{~cm}^{-1}\right)\end{array}$ & & $\begin{array}{c}K_{\mathrm{D}} \\
(\mu \mathrm{M})\end{array}$ \\
\hline FAST $^{*}$ & - & 481 & 540 & $42.5 \pm 0.8$ & $0.23 \pm 0.03$ & $0.13 \pm 0.01$ \\
cpFAST1 & 0 & 481 & 540 & $\sim 35^{* *}$ & $\sim 0.2^{\star *}$ & $5.1 \pm 0.70$ \\
cpFAST2 & 3 & 481 & 540 & $\sim 35^{* *}$ & $\sim 0.2^{\star *}$ & $0.99 \pm 0.11$ \\
cpFAST3 & 5 & 481 & 540 & $\sim 35^{* *}$ & $\sim 0.2^{\star *}$ & $0.65 \pm 0.04$ \\
cpFAST4 & 8 & 481 & 540 & $36.0 \pm 0.5$ & $0.19 \pm 0.02$ & $0.30 \pm 0.04$ \\
cpFAST5 & 11 & 481 & 542 & $36.2 \pm 0.9$ & $0.28 \pm 0.03$ & $0.22 \pm 0.03$ \\
cpFAST6 & 15 & 481 & 541 & $36.9 \pm 0.8$ & $0.24 \pm 0.03$ & $0.26 \pm 0.03$ \\
cpFAST7 & 18 & 481 & 540 & $33.0 \pm 2.9$ & $0.20 \pm 0.02$ & $0.16 \pm 0.01$ \\
\hline
\end{tabular}

${ }^{*}$ previously reported ${ }^{12}$.

** Molar absorption coefficients and quantum yields for cpFAST1, cpFAST2 and cpFAST3 are approximate numbers due to restrictions imposed on the maximum amount of complex that can be formed in solution given the reported $K_{D}$ (i.e., only at appreciably high protein concentrations will $\sim 100 \%$ of complex be formed). 
Table 2. Physico-chemical properties of the cpFAST-based $\mathrm{Ca}^{2+}$ biosensors (M13Reporter-CaM) labeled with HMBR (A) and HBR-3,5-DOM (B). Abbreviations are as follows: $K_{\mathrm{D},+}$ and $K_{\mathrm{D},-}$ are the thermodynamic dissociation constants of the sensor:fluorogen complexes in presence and in absence of $\mathrm{Ca}^{2+} ; K_{\mathrm{D}, \mathrm{Ca}}$ and $n_{\mathrm{H}}$ are the thermodynamic dissociation constant and Hill coefficient associated to $\mathrm{Ca}^{2+}$ binding (the fluorogen concentration was fixed to $\left.\left(K_{\mathrm{D},+} K_{\mathrm{D},-}\right)^{1 / 2}\right)$.

\begin{tabular}{lcccc}
\hline Reporter & & $K_{\mathrm{D},+}(\mu \mathrm{M})$ & $K_{\mathrm{D},-}(\mu \mathrm{M})$ & $K_{\mathrm{D}, \mathrm{Ca}}(\mathrm{nM})\left[n_{\mathrm{H}}\right]$ \\
\hline FAST & A & $0.16 \pm 0.01$ & $0.36 \pm 0.02$ & \\
\hline cpFAST1 & A & $4.0 \pm 0.4$ & $18.2 \pm 0.8$ & $77 \pm 2[2.8 \pm 0.2]$ \\
& B & $17.4 \pm 0.8$ & $37 \pm 3$ & $63 \pm 1[4.0 \pm 0.5]$ \\
\hline cpFAST2 & A & $1.40 \pm 0.04$ & $5.2 \pm 0.1$ & $99 \pm 4[3.0 \pm 0.3]$ \\
& B & $3.9 \pm 0.1$ & $18.0 \pm 0.8$ & $82 \pm 1[3.3 \pm 0.2]$ \\
\hline cpFAST3 & A & $0.80 \pm 0.02$ & $2.9 \pm 0.1$ & $64 \pm 2[3.3 \pm 0.3]$ \\
& B & $4.2 \pm 0.2$ & $14.8 \pm 0.9$ & $57 \pm 3[2.3 \pm 0.3]$ \\
\hline cpFAST5 & A & $0.59 \pm 0.03$ & $1.39 \pm 0.03$ & \\
& B & $2.8 \pm 0.1$ & $9.1 \pm 0.4$ & \\
\hline
\end{tabular}


A

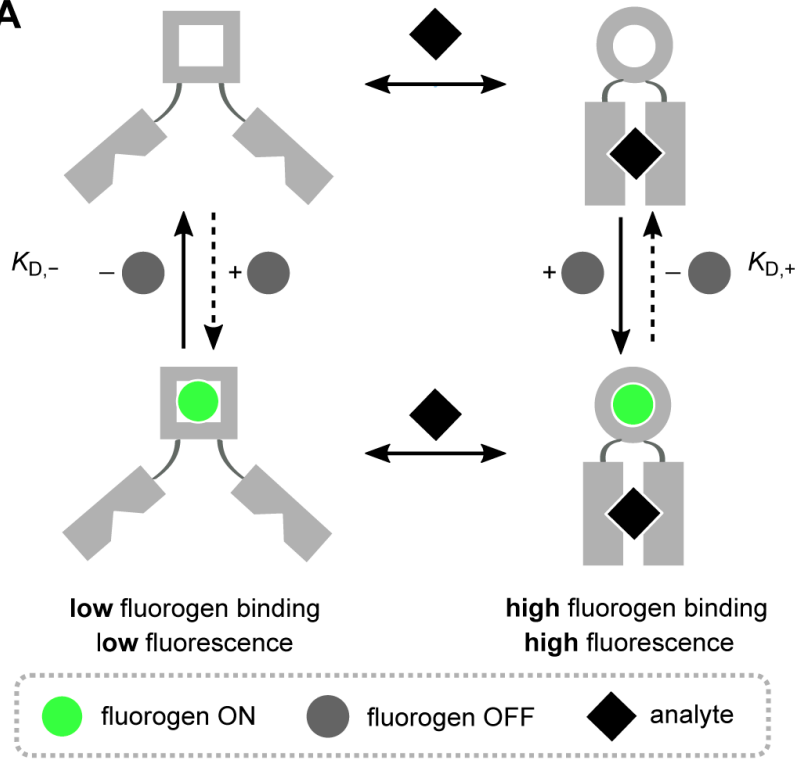

$\mathbf{F}$

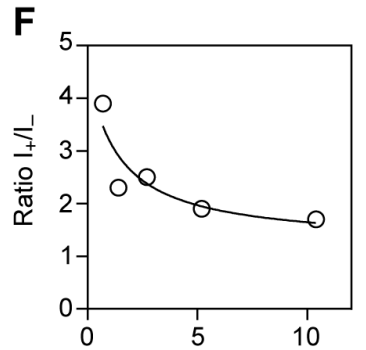

HMBR concentration ( $\mu \mathrm{M})$

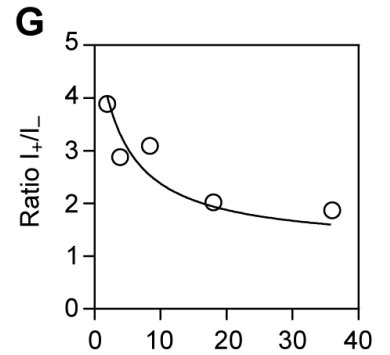

HBR-3,5-DOM concentration ( $\mu \mathrm{M})$
B

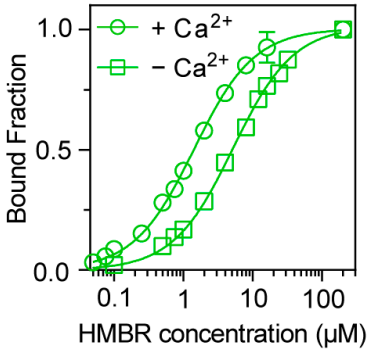

D

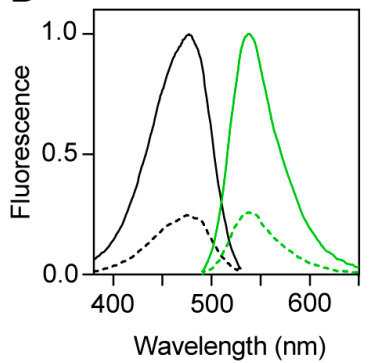

H

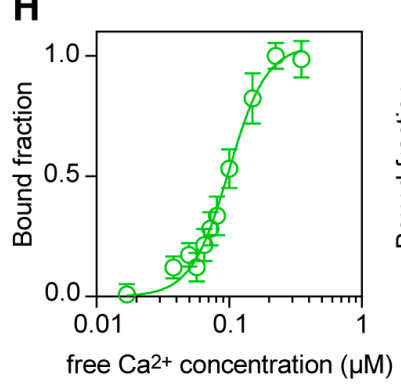

C

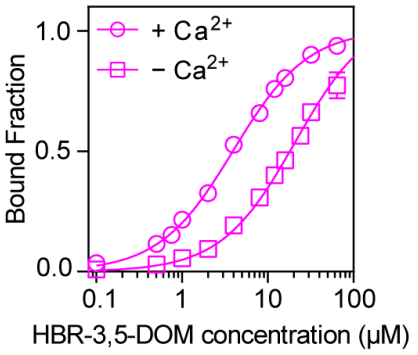

E

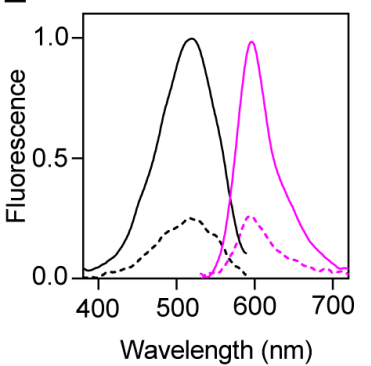

I

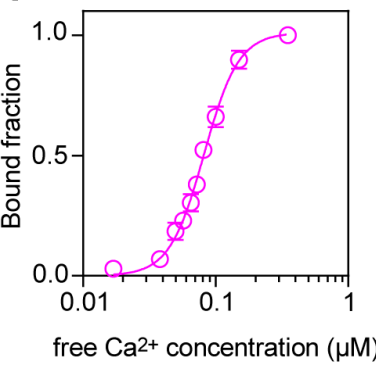

Figure 1. cpFAST-based biosensors. (A) Fluorogenic biosensors composed of a cpFAST variant coupled to analyte-recognition modules in which the binding of the fluorogenic ligand, and thus the fluorescence, is conditioned to the binding of the analyte. $K_{\mathrm{D},-}$ and $K_{\mathrm{D},+}$ are the thermodynamic dissociation constants of the sensor:fluorogen complex in the absence and the presence of analyte, respectively. (B,C) Titration curves of M13-cpFAST2-CaM in the absence or in presence of $\mathrm{Ca}^{2+}$ with either HMBR (B) or HBR$3,5 \mathrm{DOM}(\mathbf{C})$. Data represent mean $\pm \operatorname{sem}(n=3)$. Least square fit (line) gave the thermodynamic dissociation constants $K_{\mathrm{D},-}$ and $K_{\mathrm{D},+}$ provided in Table 2. (D,E) Excitation and emission spectra of M13-cpFAST2-CaM:HMBR (D) and M13-cpFAST2-CaM:HBR-3,5DOM (E) in the absence (dotted line) and presence (solid line) of $\mathrm{Ca}^{2+}$. The concentration of HMBR was $0.7 \mu \mathrm{M}$ and that of HBR-3,5-DOM $1.95 \mu \mathrm{M}$. Sensor concentration was fixed

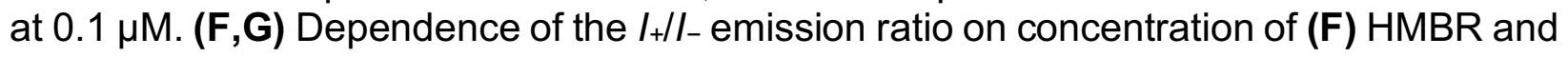
(G) HBR-3,5-DOM. (F) $I_{+}$and $I_{-}$were obtained by integrating spectra recorded at a sensor concentration of $100 \mathrm{nM}$ and HMBR concentrations of $0.7 \mu \mathrm{M}, 1.4 \mu \mathrm{M}, 2.7 \mu \mathrm{M}, 5.2 \mu \mathrm{M}$, and $10.4 \mu \mathrm{M}$ at $25^{\circ} \mathrm{C}$. (G) $I_{+}$and $I_{-}$were obtained by integrating spectra recorded at a sensor concentration of $100 \mathrm{nM}$ and HBR-3,5-DOM concentrations of $1.95 \mu \mathrm{M}, 3.9 \mu \mathrm{M}$, $8.4 \mu \mathrm{M}, 18 \mu \mathrm{M}$ and $36 \mu \mathrm{M}$ at $25^{\circ} \mathrm{C}$. $(\mathrm{H}, \mathrm{I}) \mathrm{Ca}^{2+}$ titration curve of M13-cpFAST2-CaM in the presence of $2.7 \mu \mathrm{M} \mathrm{HMBR}(\mathrm{H})$ and $8.4 \mu \mathrm{M}$ HBR-3,5DOM (I). Data represent mean \pm sem $(n=3)$. Least square fit (line) gave the thermodynamic dissociation constant $K_{D, C a}$ and Hill coefficient $n_{H}$ provided in Table 2. Sensor concentration was fixed at $0.01 \mu \mathrm{M}$. 

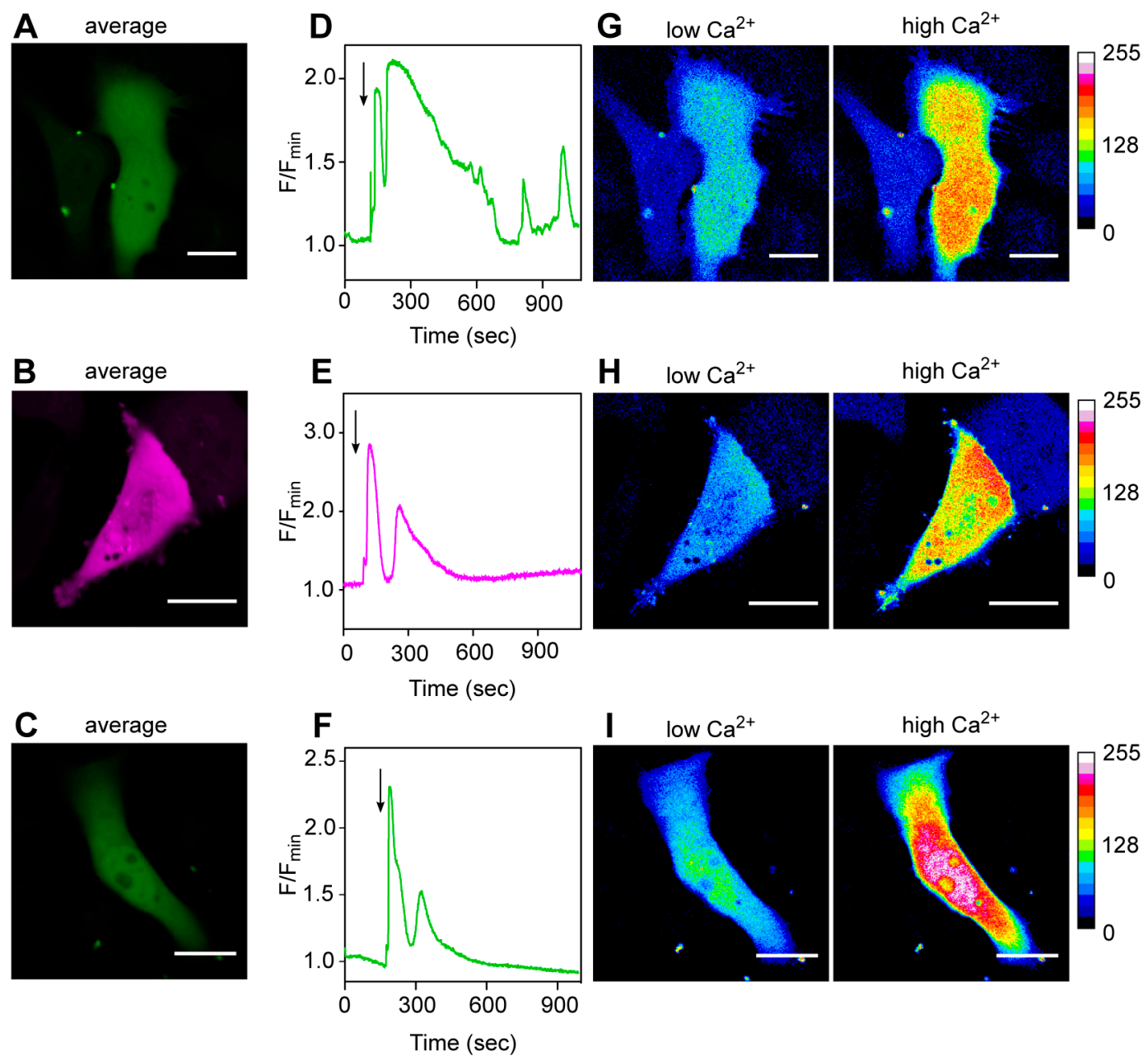

Figure 2. $\mathrm{Ca}^{2+}$ imaging in HeLa cells. M13-cpFAST2-CaM was expressed in HeLa cells and labeled with $5 \mu \mathrm{M}$ HMBR $(A, D, G)$ or $10 \mu \mathrm{M}$ HBR-3,5DOM (B,E,H). M13-cpFAST3CaM was expressed in HeLa cells and labeled with $5 \mu \mathrm{M}$ HMBR $(C, F, I)$. Cells were stimulated with $50 \mu \mathrm{M}$ histamine. Movies S1, S2 and S3 were recorded by confocal microscopy. (A-C) Average fluorescence images showing homogenous distribution of the sensors. (D-F) Fluorescence intensity changes in response to histamine addition. Time of histamine addition is indicated by the black arrow. (G-I) Low fluorescence was observed in resting state $\left(\right.$ low $\left.\mathrm{Ca}^{2+}\right)$. Histamine addition $(50 \mu \mathrm{M})$ induced a significant increase of fluorescence (high $\mathrm{Ca}^{2+}$ ), in accordance with an increase of cytosolic free $\mathrm{Ca}^{2+}$. (A-I) Scale bars $20 \mu \mathrm{m}$. 


\section{REFERENCES}

(1) Okumoto, S. (2010) Imaging approach for monitoring cellular metabolites and ions using genetically encoded biosensors. Curr. Opin. Biotechnol. 21, 45-54.

(2) Palmer, A. E., Qin, Y., Park, J. G., and McCombs, J. E. (2011) Design and application of genetically encoded biosensors. Trends in Biotechnology 29, 144-152.

(3) Frommer, W. B., Davidson, M. W., and Campbell, R. E. (2009) Genetically encoded biosensors based on engineered fluorescent proteins. Chem Soc Rev 38, 2833-18.

(4) VanEngelenburg, S. B., and Palmer, A. E. (2008) Fluorescent biosensors of protein function. Curr. Op. Chem. Biol. 12, 60-65.

(5) Bruchez, M. P. (2015) Dark dyes-bright complexes: fluorogenic protein labeling. Curr. Op. Chem. Biol. 27, 18-23.

(6) Jullien, L., and Gautier, A. (2015) Fluorogen-based reporters for fluorescence imaging: a review. Methods Appl. Fluoresc. 3, 042007-13.

(7) Li, C., Tebo, A. G., and Gautier, A. (2017) Fluorogenic Labeling Strategies for Biological Imaging. IJMS 18, 1473-11.

(8) Paige, J. S., Wu, K. Y., and Jaffrey, S. R. (2011) RNA Mimics of Green Fluorescent Protein. Science 333, 642-646.

(9) Paige, J. S., Nguyen-Duc, T., Song, W., and Jaffrey, S. R. (2012) Fluorescence imaging of cellular metabolites with RNA. Science 335, 1194-1194.

(10) You, M., Litke, J. L., and Jaffrey, S. R. (2015) Imaging metabolite dynamics in living cells using a Spinach-based riboswitch. Proc. Natl. Acad. Sci. U. S. A 112, E2756-65.

(11) Plamont, M.-A., Billon-Denis, E., Maurin, S., Gauron, C., Pimenta, F. M., Specht, C. G., Shi, J., Querard, J., Pan, B., Rossignol, J., Morellet, N., Volovitch, M., Lescop, E., Chen, Y., Triller, A., Vriz, S., Le Saux, T., Jullien, L., and Gautier, A. (2016) Small fluorescence-activating and absorption-shifting tag for tunable protein imaging in vivo. Proc. Natl. Acad. Sci. U. S. A 113, 497-502.

(12) Li, C., Plamont, M.-A., Sladitschek, H. L., Rodrigues, V., Aujard, I., Neveu, P., Le Saux, T., Jullien, L., and Gautier, A. (2017) Dynamic multicolor protein labeling in living cells. Chem. Sci. 8, 5598-5605.

(13) Nakai, J., Ohkura, M., and Imoto, K. (2001) A high signal-to-noise $\mathrm{Ca}(2+)$ probe composed of a single green fluorescent protein. Nat Biotechnol 19, 137-141.

(14) Zhao, Y., Araki, S., Wu, J., Teramoto, T., Chang, Y.-F., Nakano, M., Abdelfattah, A. S., Fujiwara, M., Ishihara, T., Nagai, T., and Campbell, R. E. (2011) An expanded palette of genetically encoded $\mathrm{Ca}^{2+}$ indicators. Science 333, 1888-1891.

(15) Marvin, J. S., Borghuis, B. G., Tian, L., Cichon, J., Harnett, M. T., Akerboom, J., Gordus, A., Renninger, S. L., Chen, T.-W., Bargmann, C. I., Orger, M. B., Schreiter, E. R., Demb, J. B., Gan, W.-B., Hires, S. A., and Looger, L. L. (2013) An optimized fluorescent probe for visualizing glutamate neurotransmission. Nat. Methods 10, 162-170.

(16) Kumar, A., Burns, D. C., Al-Abdul-Wahid, M. S., and Woolley, G. A. (2013) A circularly permuted photoactive yellow protein as a scaffold for photoswitch design. Biochemistry 52, 3320-3331.

(17) Chen, T.-W., Wardill, T. J., Sun, Y., Pulver, S. R., Renninger, S. L., Baohan, A., Schreiter, E. R., Kerr, R. A., Orger, M. B., Jayaraman, V., Looger, L. L., Svoboda, K., and Kim, D. S. (2013) Ultrasensitive fluorescent proteins for imaging neuronal activity. 
Nature 499, 295-300.

(18) Berridge, M. J., Bootman, M. D., and Roderick, H. L. (2003) Calcium signalling: dynamics, homeostasis and remodelling. Nat Rev Mol Cell Biol 4, 517-529.

(19) Porumb, T., Yau, P., Harvey, T. S., and Ikura, M. (1994) A calmodulin-target peptide hybrid molecule with unique calcium-binding properties. Protein Eng. 7, 109-115. (20) Miyawaki, A., Llopis, J., Heim, R., McCaffery, J. M., Adams, J. A., Ikura, M., and Tsien, R. Y. (1997) Fluorescent indicators for Ca2+ based on green fluorescent proteins and calmodulin. Nature 388, 882-887.

(21) Bootman, M. D., Cheek, T. R., Moreton, R. B., Bennett, D. L., and Berridge, M. J. (1994) Smoothly graded Ca2+ release from inositol 1,4,5-trisphosphate-sensitive Ca2+ stores. J. Biol. Chem. 269, 24783-24791.

(22) Akerboom, J., Rivera, J. D. V., Guilbe, M. M. R., Malavé, E. C. A., Hernandez, H. H., Tian, L., Hires, S. A., Marvin, J. S., Looger, L. L., and Schreiter, E. R. (2009) Crystal structures of the GCaMP calcium sensor reveal the mechanism of fluorescence signal change and aid rational design. J. Biol. Chem. 284, 6455-6464.

(23) Shitashima, Y., Shimozawa, T., Asahi, T., and Miyawaki, A. (2018) A dual-ligandmodulable fluorescent protein based on UnaG and calmodulin. Biochem. Biophys. Res. Comm. 496, 872-879.

(24) Wu, J., Abdelfattah, A. S., Zhou, H., Ruangkittisakul, A., Qian, Y., Ballanyi, K., and Campbell, R. E. (2018) Genetically Encoded Glutamate Indicators with Altered Color and Topology. ACS Chem. Biol.

(25) Qin, Y., Sammond, D. W., Braselmann, E., Carpenter, M. C., and Palmer, A. E. (2016) Development of an Optical Zn 2+Probe Based on a Single Fluorescent Protein. ACS Chem. Biol. 11, 2744-2751.

(26) Chen, Z., and Ai, H.-W. (2016) Single Fluorescent Protein-Based Indicators for Zinc Ion (Zn 2+). Anal. Chem. 88, 9029-9036.

(27) Sanford, L., and Palmer, A. (2017) Recent Advances in Development of Genetically Encoded Fluorescent Sensors. Meth. Enzymol. 589, 1-49. 


\title{
Supporting Information
}

\section{Circularly permuted fluorogenic proteins for the design of modular biosensors}

\author{
Alison G. Tebo ${ }^{1, \#}$, Frederico M. Pimenta ${ }^{1, \#}$, Martha Zoumpoulaki ${ }^{1}$, Carlos Kikuti' ${ }^{2}$, Helena \\ Sirkia ${ }^{2}$, Marie-Aude Plamont ${ }^{1}$, Anne Houdusse ${ }^{2} \&$ Arnaud Gautier $^{1, *}$ \\ ${ }^{1}$ PASTEUR, Département de Chimie, École Normale Supérieure, PSL \\ University, Sorbonne Université, CNRS, 75005 Paris, France. \\ ${ }^{2}$ Structural Motility, Institut Curie, PSL Research University, CNRS, UMR 144, F-75005 \\ Paris, France. \\ \#Equal contributions \\ *Correspondence should be addressed to: arnaud.gautier@ens.fr
}

\section{Content}

Legends of Movies S1-S3

SI Text 1

SI Figures: Figures S1-S14

Materials \& Methods

SI References 


\section{Legends of Movies}

Movie S1: $\mathrm{Ca}^{2+}$ imaging in HeLa cells using M13-cpFAST2-CaM and HMBR. M13cpFAST2-CaM was expressed in HeLa cells and labeled with $5 \mu \mathrm{M}$ HMBR. Cells were stimulated with $50 \mu \mathrm{M}$ of histamine at $\mathrm{t}=100 \mathrm{~s}$.

Movie S2: $\mathrm{Ca}^{2+}$ imaging in HeLa cells using M13-cpFAST2-CaM and HBR-3,5-DOM. M13-cpFAST2-CaM was expressed in HeLa cells and labeled with $10 \mu \mathrm{M}$ HBR-3,5-DOM. Cells were stimulated with $50 \mu \mathrm{M}$ of histamine at $\mathrm{t}=80 \mathrm{~s}$.

Movie S3: $\mathrm{Ca}^{2+}$ imaging in HeLa cells using M13-cpFAST3-CaM and HMBR. M13cpFAST3-CaM was expressed in HeLa cells and labeled with $5 \mu \mathrm{M}$ HMBR. Cells were stimulated with $50 \mu \mathrm{M}$ of histamine at $\mathrm{t}=160 \mathrm{~s}$. 


\section{SI Text 1}

When the total concentration of fluorogen $\left(F_{\text {tot }}\right)$ is large compared to the total concentration of sensor $\left(S_{\text {tot }}\right)$, one can write the fraction of sensor:fluorogen complex $(\alpha)$ as:

$$
\alpha=\frac{1}{\frac{K_{\mathrm{D}}}{F_{\mathrm{tot}}}+1}
$$

, where $K_{D}$ is the thermodynamic dissociation constant of the sensor:fluorogen complex.

To characterize the response of a fluorogen-based sensor upon analyte binding, one can either compute the variation of complex fraction upon analyte binding:

$$
\alpha_{+}-\alpha_{-}=\frac{1}{\frac{K_{\mathrm{D},+}}{F_{\text {tot }}}+1}-\frac{1}{\frac{K_{\mathrm{D},-}}{F_{\text {tot }}}+1}
$$

or the increase of bound fraction upon analyte binding:

$$
\alpha_{+} / \alpha_{-}=\frac{\frac{K_{\mathrm{D},-}}{F_{\mathrm{tot}}}+1}{\frac{K_{\mathrm{D},+}}{F_{\mathrm{tot}}}+1}
$$

, where $\alpha_{+}$and $\alpha_{-}$are respectively the fraction of sensor:fluorogen complex in excess and in absence of analyte, and $K_{\mathrm{D},+}$ and $K_{\mathrm{D},-}$ are respectively the thermodynamic dissociation constants of the sensor:fluorogen complex in excess and in absence of analyte.

One can easily show that $\alpha_{+}-\alpha_{-}$is optimal when $F_{\mathrm{tot}}=\left(K_{\mathrm{D},+} K_{\mathrm{D},-}\right)^{1 / 2}$, while $\alpha_{+} / \alpha_{-}$ is maximal at small $F_{\text {tot. }}$

By noting $I_{\mathrm{F},+}$ and $I_{\mathrm{F},-}$ the fluorescence intensities in presence and in absence of the analyte, the fluorescence dynamic range of the sensor is given by: 


$$
\frac{I_{\mathrm{F},+}}{I_{\mathrm{F},-}}=\frac{B_{+} \alpha_{+}}{B_{-} \alpha_{-}}
$$

where $B_{+}$and $B_{-}$are respectively the brightness of the sensor:fluorogen complex in presence and in absence of analyte. The dynamic range depends thus on the concentration in fluorogen $F_{\text {tot }}$ and is maximal at low $F_{\text {tot, }}$ approaching the value

$$
\frac{B_{+}}{B_{-}} \frac{K_{\mathrm{D},-}}{K_{\mathrm{D},+}}
$$

However, $F_{\text {tot }}$ must be high enough to allow the detection of the fluorescent complex, (See Figure S8). We propose that the ideal compromise to obtain both good dynamic range and satisfactory detection sensitivity is to choose $F_{\text {tot }}$ in the range:

$$
K_{\mathrm{D},+} / 2 \leq F_{\mathrm{tot}} \leq\left(K_{\mathrm{D},+} K_{\mathrm{D},-}\right)^{1 / 2}
$$

The fluorogen concentration may be eventually tuned relative to the needs of the experiment - lower, when the signal ratio must be optimized, or higher when overall fluorescence signal is important.

To evaluate the dynamic range of our sensor, we measured the fluorescence fold increase in a range of fluorogen concentrations $-K_{\mathrm{D},+} / 2, \mathrm{~K}_{\mathrm{D},+},\left(K_{\mathrm{D},+} K_{\mathrm{D},-}\right)^{1 / 2}, K_{\mathrm{D},-}$, and $2 K_{\mathrm{D},-}$ - chosen so as to sample a large range of conditions and expected fluorescence fold increases 


\section{SI Figures}

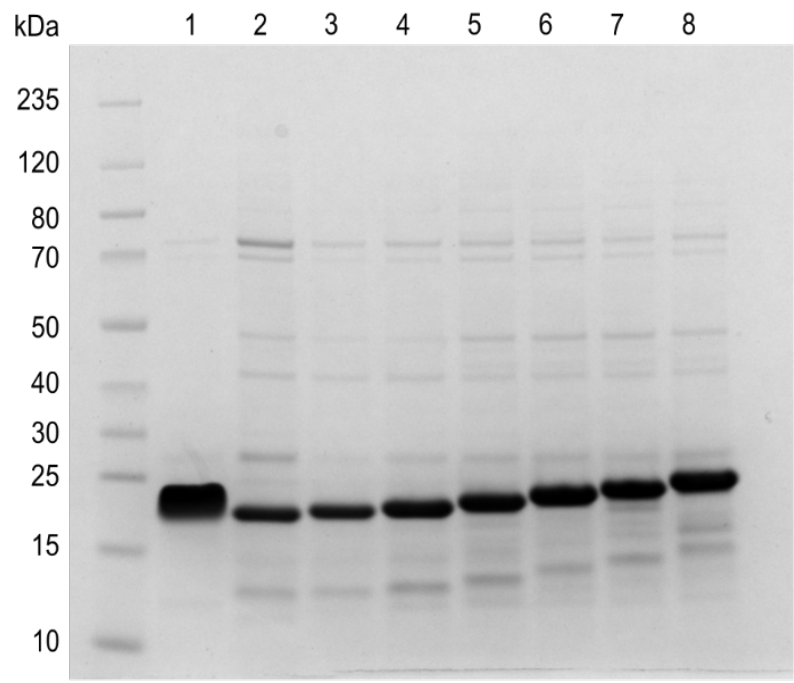

Figure S1. Bacterial expression and purification of the circularly permuted FAST variants. Coomassie-stained SDS-PAGE of purified 1: FAST, 2: cpFAST1, 3: cpFAST2, 4: cpFAST3, 5: cpFAST4, 6: cpFAST5, 7: cpFAST6, 8: cpFAST7. 
A

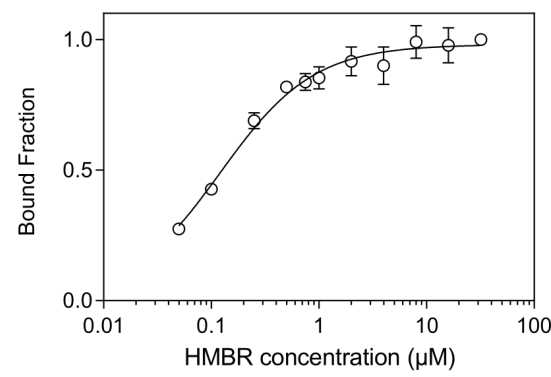

D

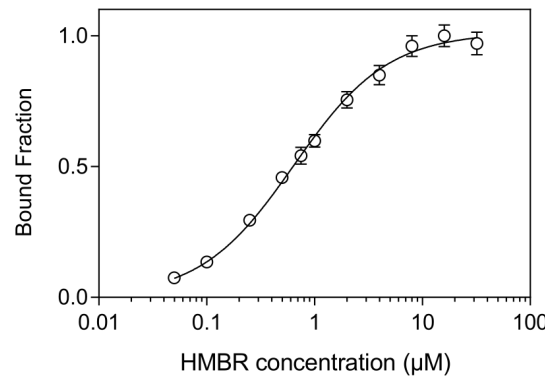

G

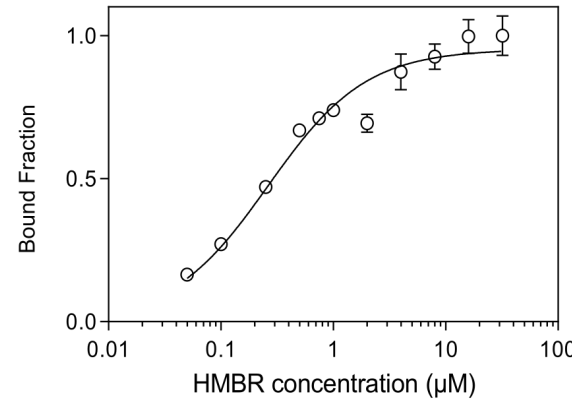

C
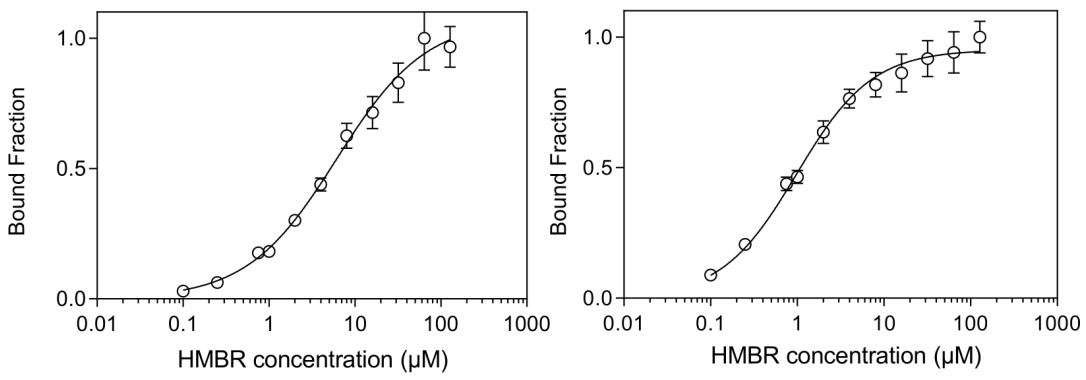

F
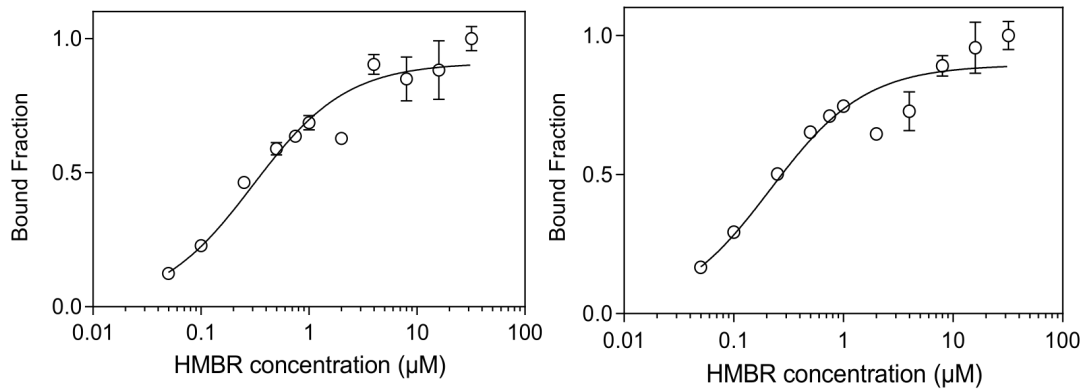

H

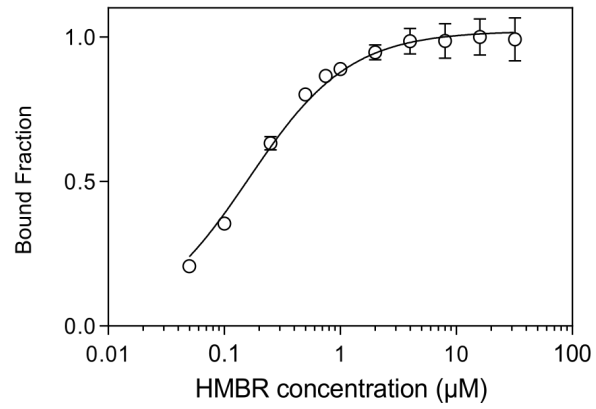

Figure S2. HMBR titration curves of (A) FAST, (B) cpFAST1, (C) cpFAST2, (D) cpFAST3, (E) cpFAST4, (F) cpFAST5, (G) cpFAST6, (H) cpFAST7. Titrations were done at a protein concentration of $50 \mathrm{nM}$ in pH 7.4 PBS buffer at $25^{\circ} \mathrm{C}$. Data represent mean $\pm \operatorname{sem}(n=3)$. Least square fit (line) gave the thermodynamic dissociation constants $K_{\mathrm{D}}$ provided in Table 1. 


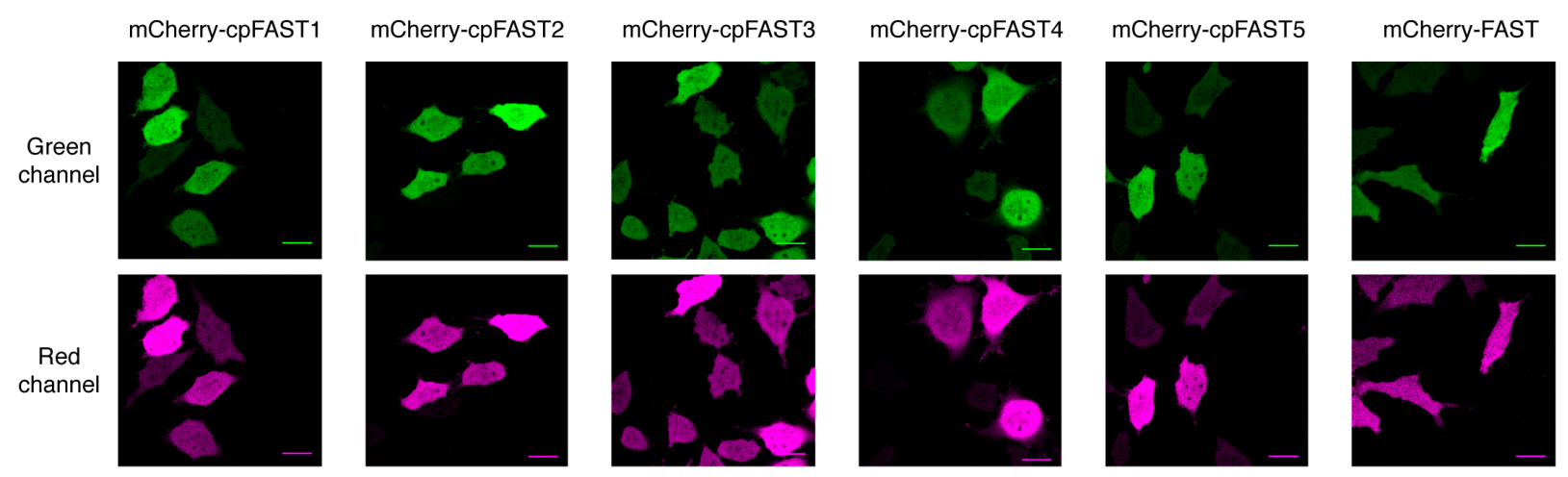

Figure S3. Characterization of cpFAST in mammalian cells. Confocal images of HeLa cells expressing the circularly permuted FAST variants fused to the red fluorescent protein mCherry. The green channel shows the fluorescence signal from the FAST variants labeled with concentrations of HMBR ensuring full labeling of FAST ( $50 \mu \mathrm{M}$ for cpFAST1, $40 \mu \mathrm{M}$ for cpFAST2, $15 \mu \mathrm{M}$ for cpFAST3, $10 \mu \mathrm{M}$ for cpFAST4 and $6 \mu \mathrm{M}$ for $\mathrm{cpFAST} 5$, and $5 \mu \mathrm{M}$ for FAST5), while the red channel shows the fluorescence signal from mCherry. Side-by-side images were recorded with the same settings for direct comparison. Scale bars $20 \mu \mathrm{m}$. 


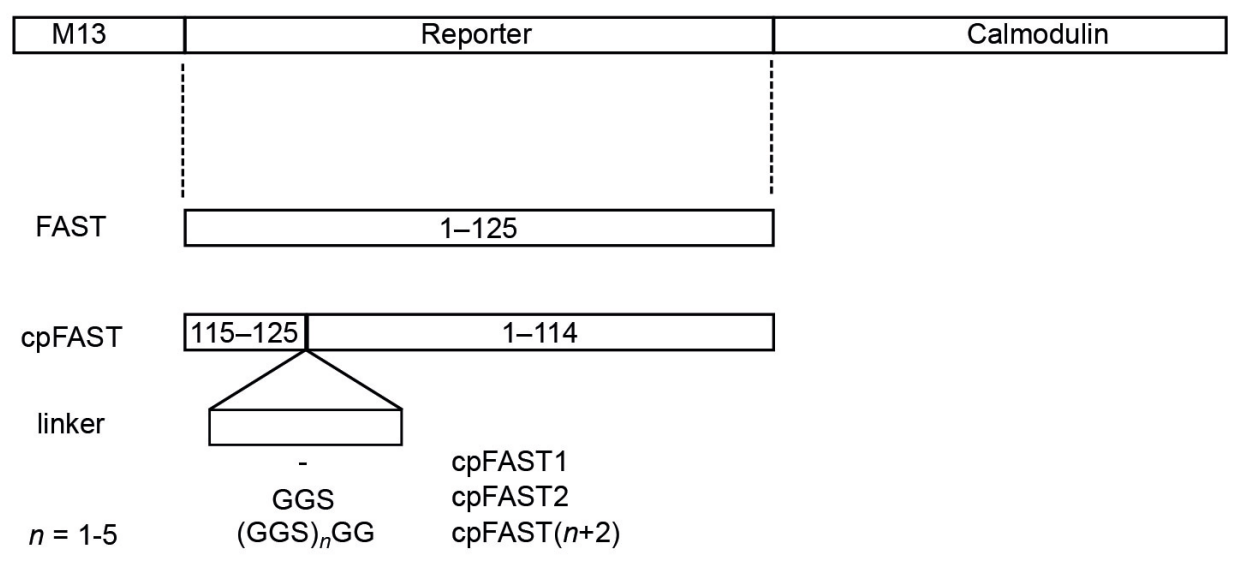

Figure S4. FAST-based $\mathrm{Ca}^{2+}$ biosensors. FAST-based $\mathrm{Ca}^{2+}$ biosensors were constructed by connecting the N-terminus of FAST or cpFAST to the M13 peptide, and its C-terminus to Calmodulin. 


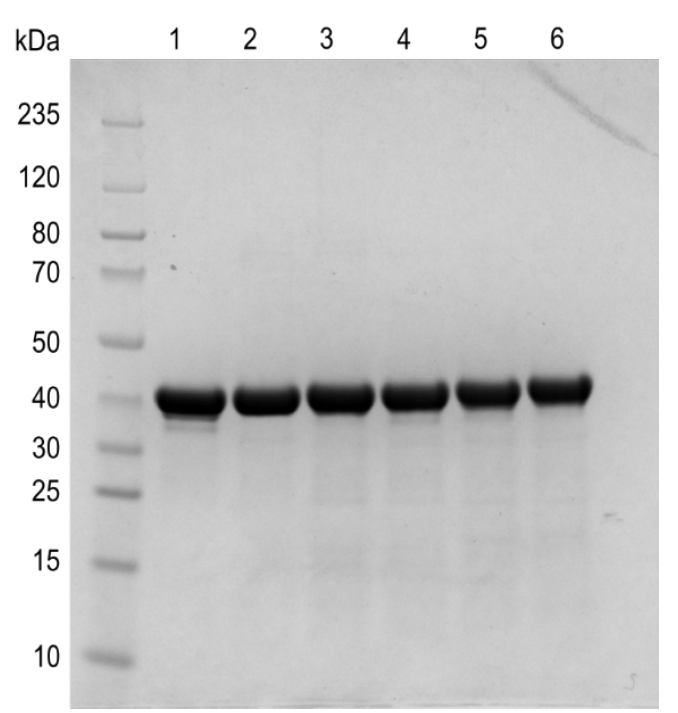

Figure S5. Bacterial expression and purification of the FAST-based $\mathrm{Ca}^{2+}$ biosensors. Coomassie-stained SDS-PAGE of purified 1: M13-FAST-CaM, 2: M13cpFAST1-CaM, 3: M13-cpFAST2-CaM, 4: M13-cpFAST3-CaM, 5: M13-cpFAST4-CaM, 6: M13-cpFAST5-CaM. 

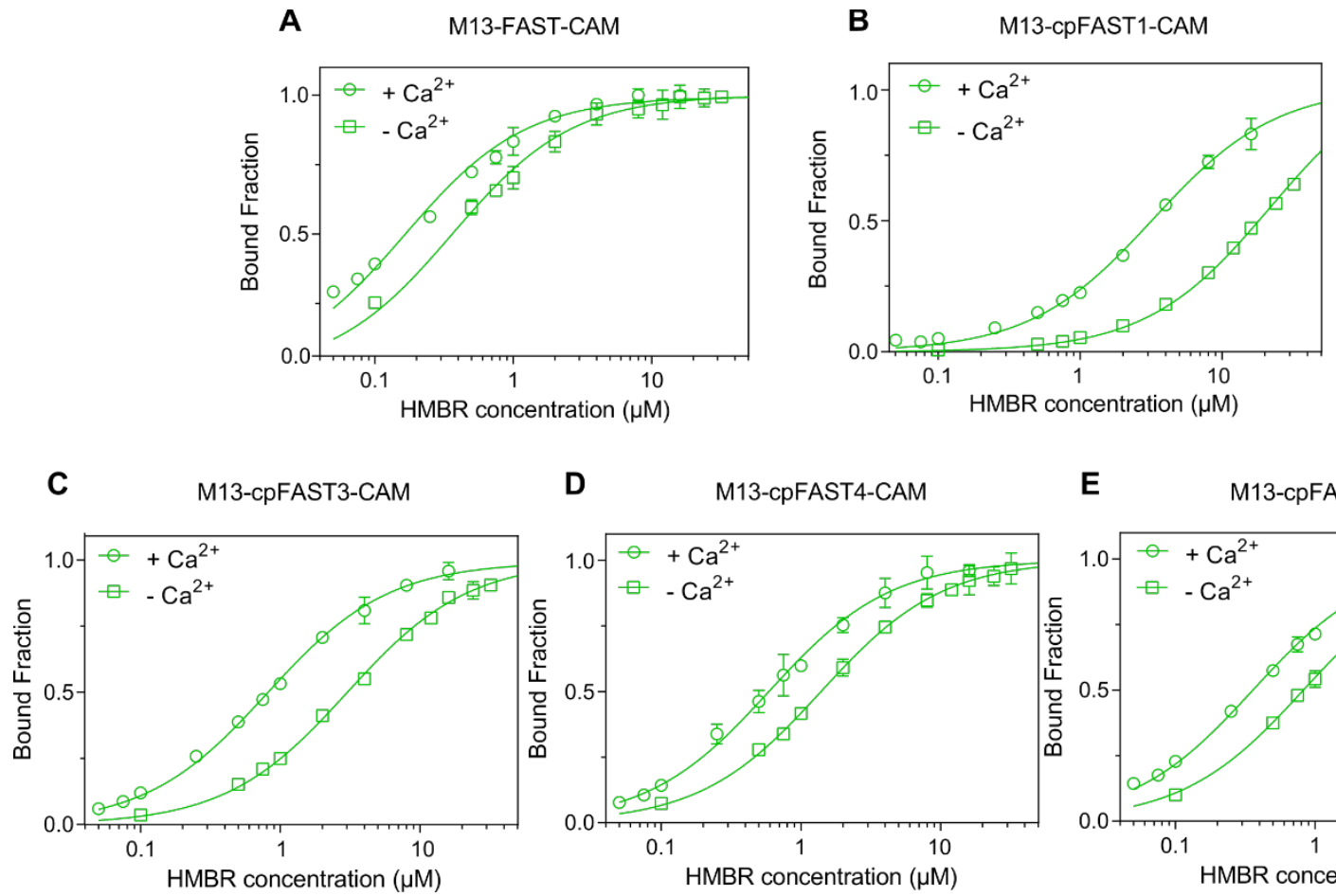

D

E M13-cpFAST5-CAM
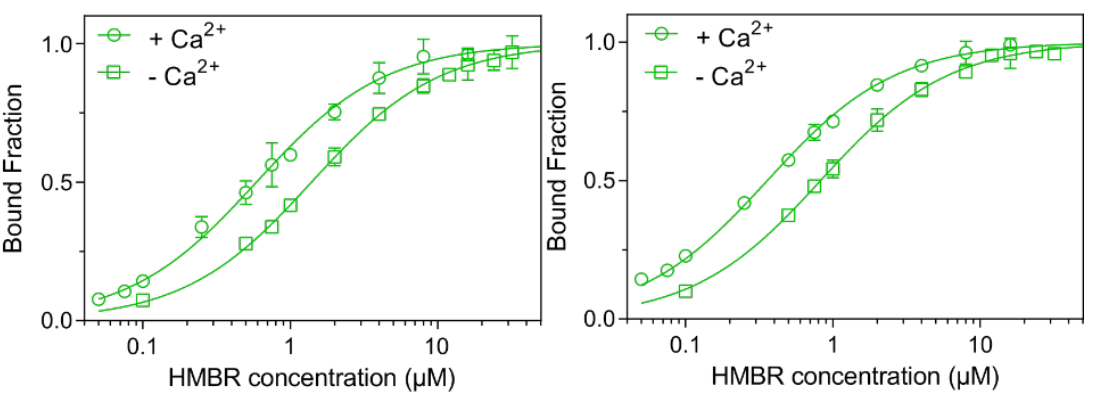

Figure S6. HMBR titration curves of the FAST-based $\mathrm{Ca}^{2+}$ biosensors in the presence and absence of $\mathrm{Ca}^{2+}$. (A) M13-FAST-CaM, (B) M13-cpFAST1-CaM, (C) M13cpFAST3-CaM, (D) M13-cpFAST4-CaM, (E) M13-cpFAST5-CaM. Titrations were done at a sensor concentration of $100 \mathrm{nM}$ in pH 7.4 HEPES buffer containing $10 \mathrm{mM} \mathrm{CaCl}_{2}$ (+ $^{+}$ $\left.\mathrm{Ca}^{2+}\right)$ or $10 \mathrm{mM} \mathrm{EGTA}\left(-\mathrm{Ca}^{2+}\right)$ at $25^{\circ} \mathrm{C}$. Excitation was fixed at $480 \mathrm{~nm}$ and emission at $540 \mathrm{~nm}$. Data represent mean $\pm \operatorname{sem}(\mathrm{n}=3)$. Least square fit (line) gave the thermodynamic dissociation constants $K_{\mathrm{D},-}$ and $K_{\mathrm{D},+}$ provided in Table 2. 
A

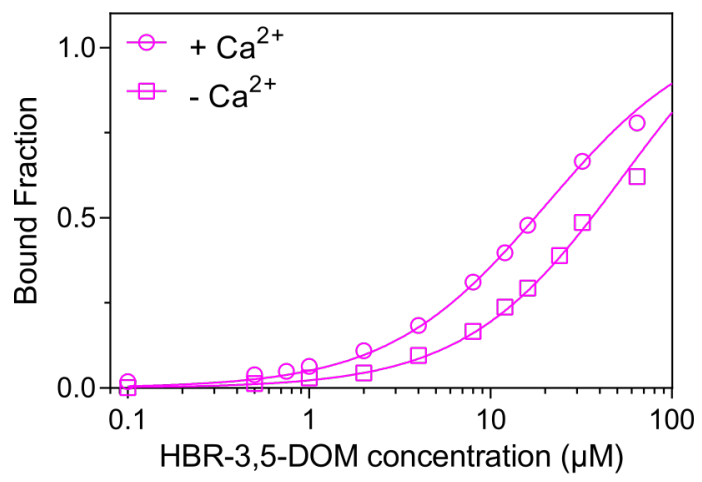

C

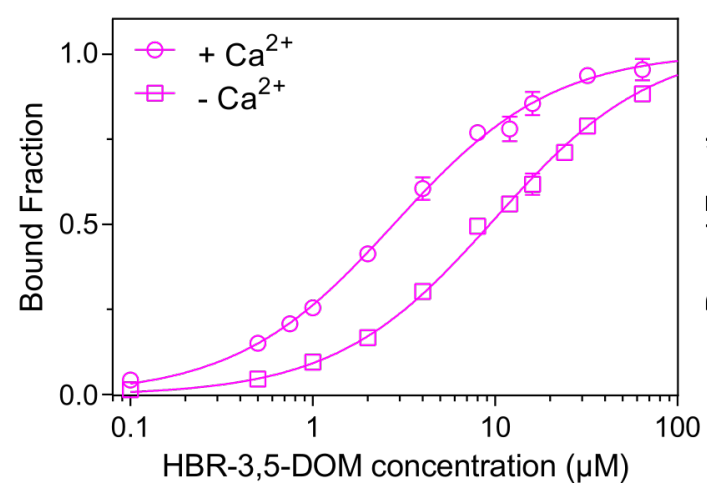

B M13-cpFAST3-CAM

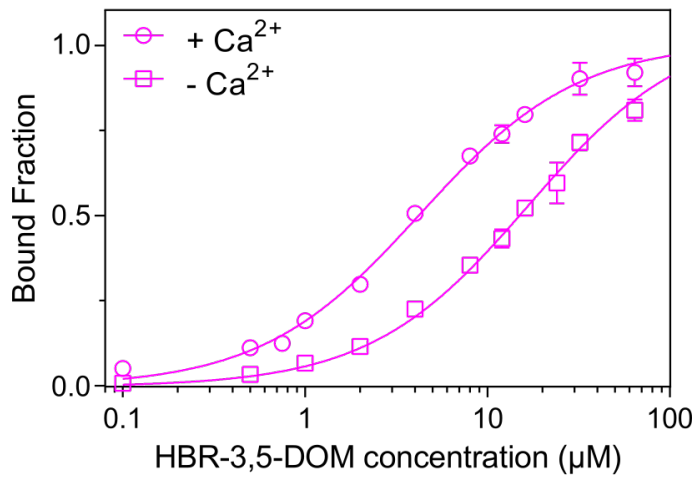

D M13-cpFAST5-CAM

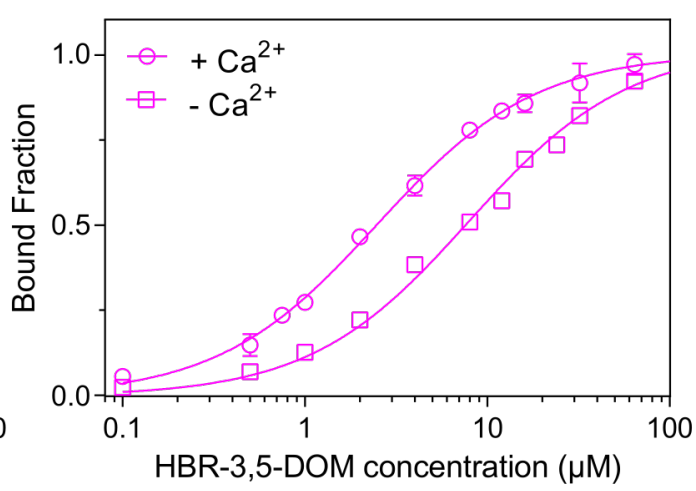

Figure S7. HBR-3,5-DOM titration curves of the FAST-based $\mathrm{Ca}^{2+}$ biosensors in the presence and absence of $\mathrm{Ca}^{2+}$. (A) M13-cpFAST1-CaM, (B) M13-cpFAST3-CaM, (C) M13-cpFAST4-CaM, (D) M13-cpFAST5-CaM. Titrations were done at a sensor concentration of $100 \mathrm{nM}$ in pH 7.4 HEPES buffer containing $10 \mathrm{mM} \mathrm{CaCl}_{2}\left(+\mathrm{Ca}^{2+}\right)$ or 10 mM EGTA $\left(-\mathrm{Ca}^{2+}\right)$ at $25^{\circ} \mathrm{C}$. Excitation was fixed at $520 \mathrm{~nm}$ and emission at $600 \mathrm{~nm}$. Data represent mean \pm sem $(n=3)$. Least square fit (line) gave the thermodynamic dissociation constants $K_{\mathrm{D},-}$ and $K_{\mathrm{D},+}$ provided in Table 2. 


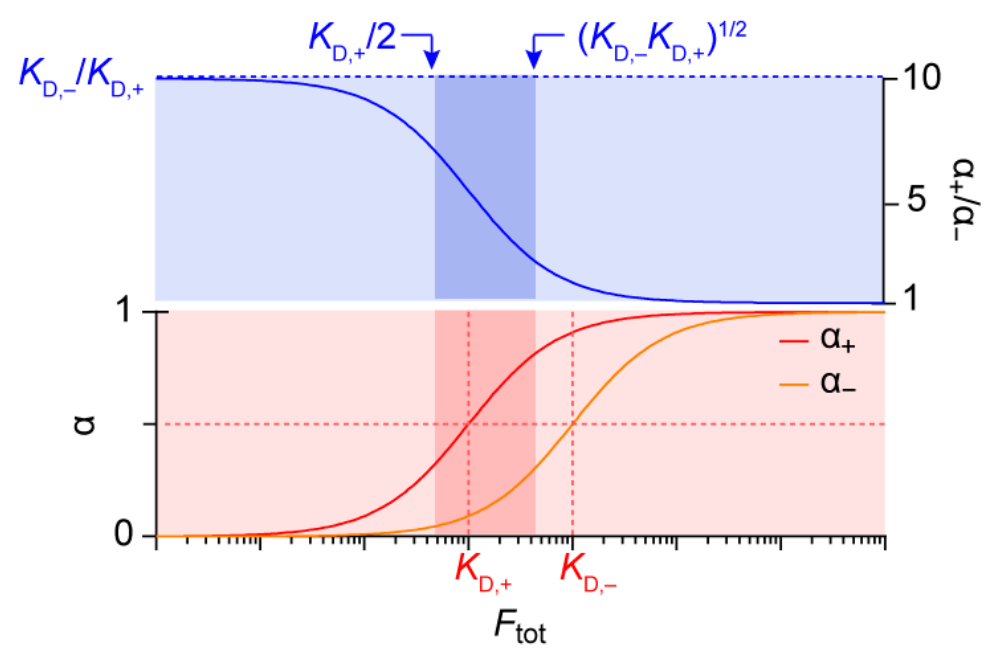

Figure S8. FAST-based optical biosensors. Simulated fluorogen binding curves in the presence and absence of analyte (with $\left.K_{\mathrm{D},-}=10 K_{\mathrm{D},+}\right) . \alpha_{+}$and $\alpha_{-}$are the fluorogen bound fractions in presence and absence of the analyte, respectively. Choosing the concentration of fluorogen between $K_{\mathrm{D},+} / 2$ and $\left(K_{\mathrm{D},+} K_{\mathrm{D},-}\right)^{1 / 2}$ (contrasted rectangles) is a good compromise to obtain both good dynamic range and satisfactory detection sensitivity. 
A

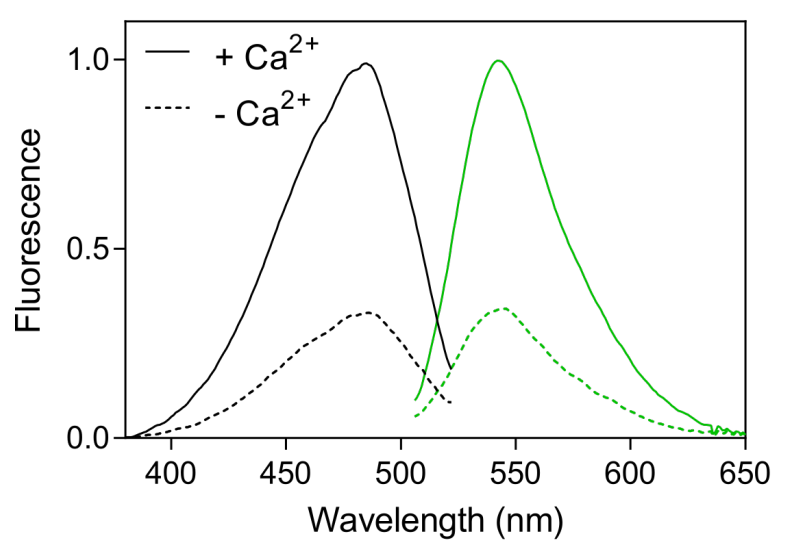

B

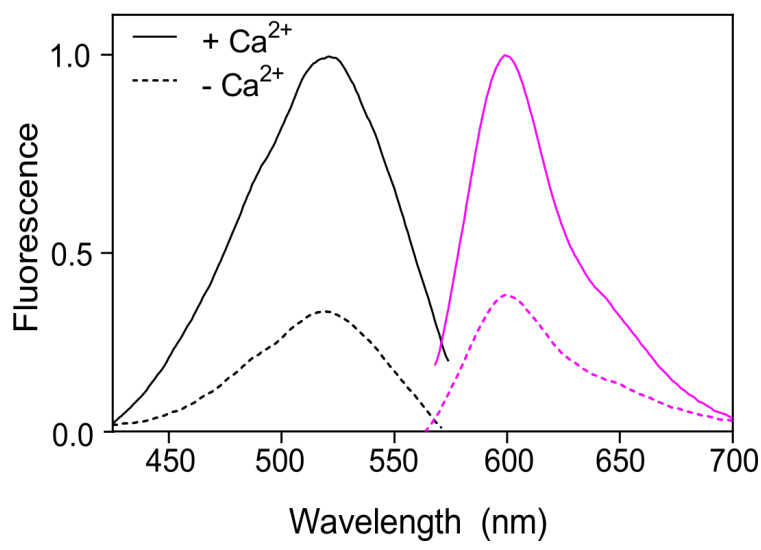

Figure S9. Excitation and Emission spectra of (A) M13-cpFAST3-CaM:HMBR and (B) M13-cpFAST3-CaM:HBR-3,5DOM in the absence (dashed lines) and presence of $\mathrm{Ca}^{2+}$ (solid lines). Spectra were recorded at a sensor concentration of $100 \mathrm{nM}$ and a fluorogen concentration of $\left(K_{\mathrm{D},+} K_{D,-}\right)^{1 / 2}$ at $25^{\circ} \mathrm{C}$. Excitation was scanned from 380 to 530 $\mathrm{nm}$ at $540 \mathrm{~nm}$ emission andemission was scanned from 490 to $650 \mathrm{~nm}$ at $480 \mathrm{~nm}$ excitation. 

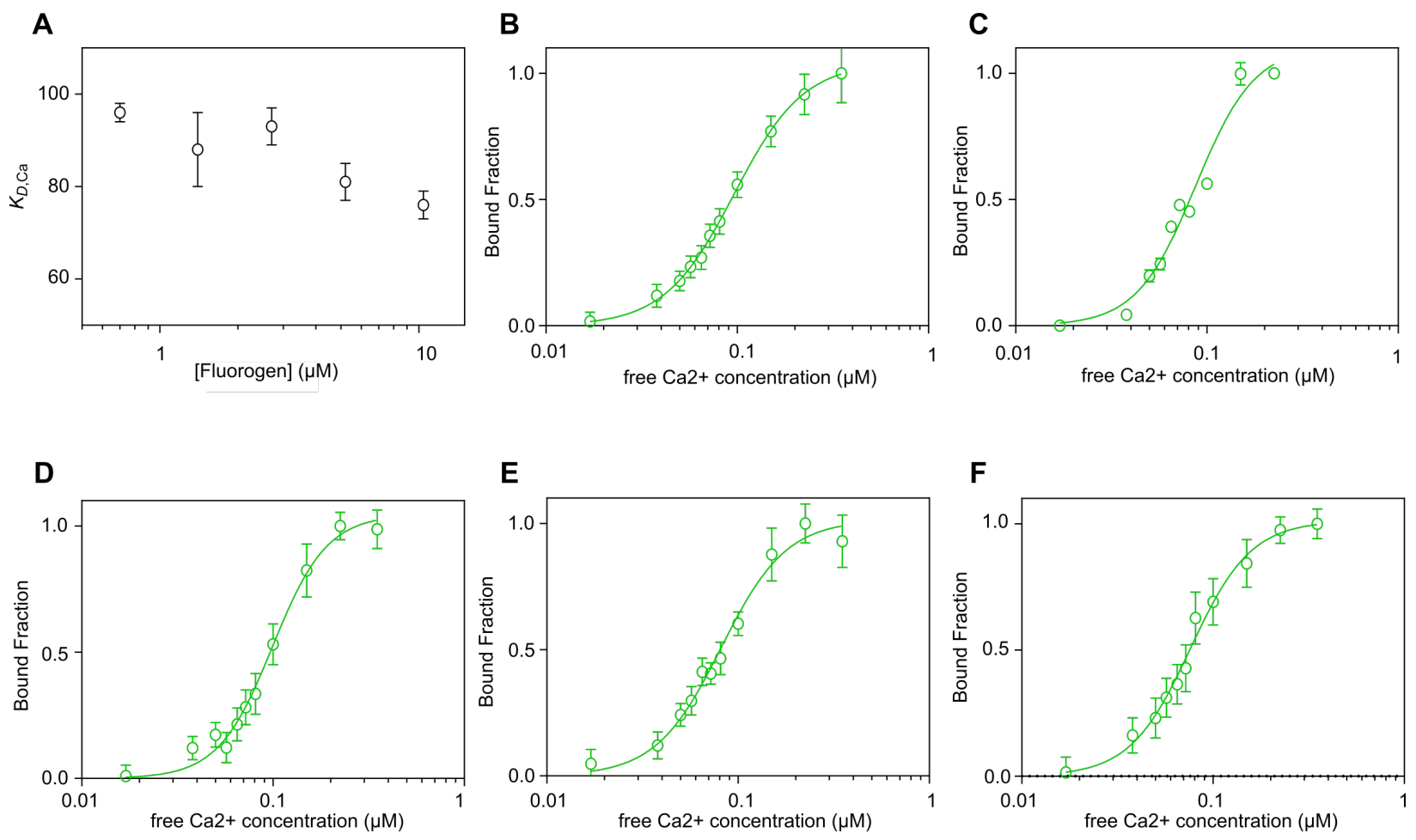

Figure S10. (A) Dependence of $K_{D, C a}$ on HMBR concentration for M13-cpFAST2-CaM (B-F).Titrations were done at a sensor concentration of $10 \mathrm{nM}$ and HMBR concentrations of (B) $0.7 \mu \mathrm{M}$ (C) $1.4 \mu \mathrm{M}$ (D) $2.7 \mu \mathrm{M}$, (E) $5.4 \mu \mathrm{M}$ and (F) $10.4 \mu \mathrm{M}$. Excitation was fixed at $480 \mathrm{~nm}$ and emission at $540 \mathrm{~nm}$. Data represent mean \pm sem $(n=3)$. Least square fit (line) gave the thermodynamic dissociation constant $K_{\mathrm{D}, \mathrm{Ca}}$ and Hill coefficient $n_{\mathrm{H}}$. 

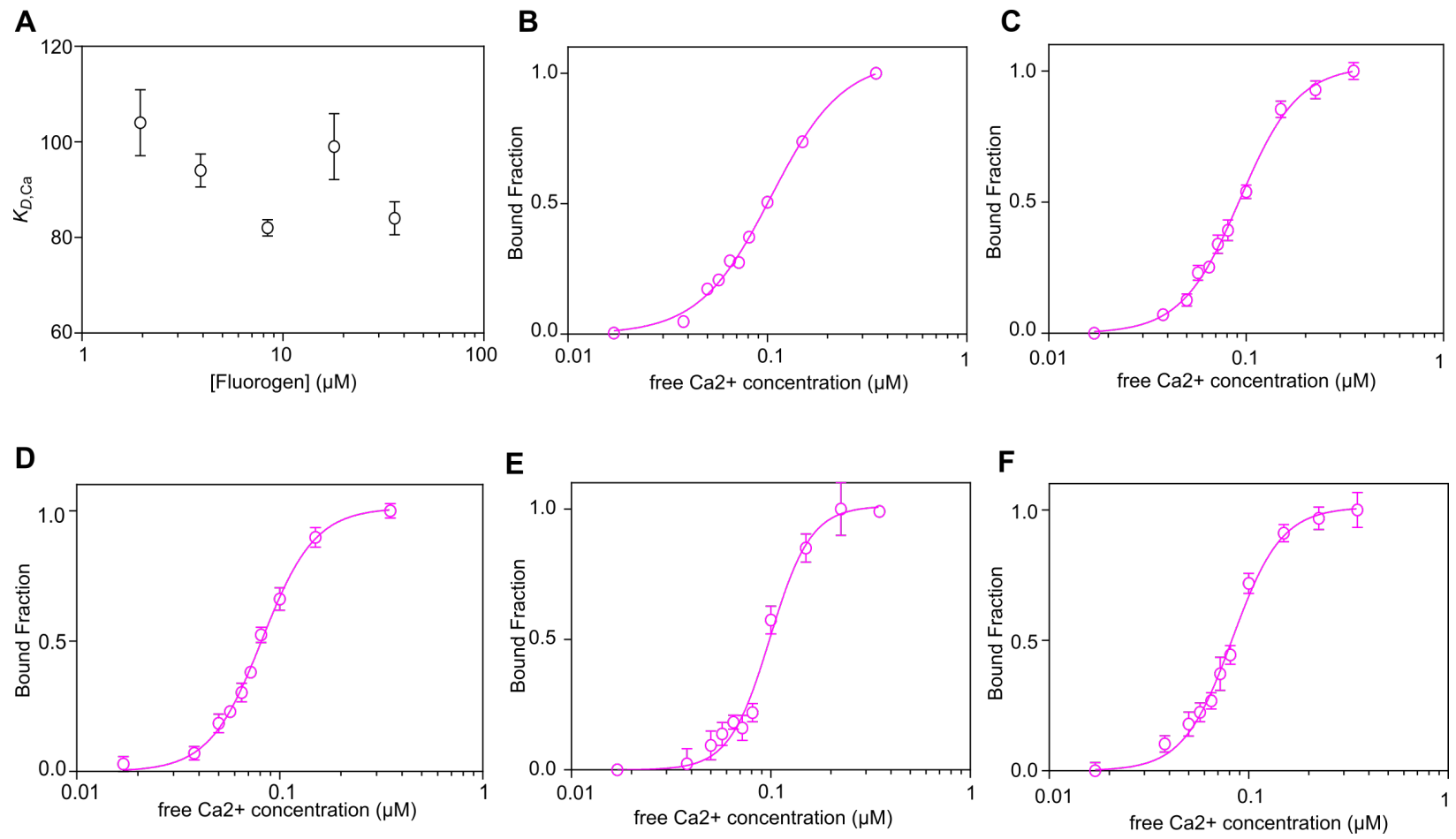

Figure S11. (A) Dependence of $K_{D, C a}$ on HBR-3,5DOM concentration for M13-cpFAST2CaM (B-F).Titrations were done at a sensor concentration of $10 \mathrm{nM}$ and HBR-3,5DOM concentrations of (B) $1.95 \mu \mathrm{M}$ (C) $3.9 \mu \mathrm{M}$ (D) $8.4 \mu \mathrm{M}$, (E) $18 \mu \mathrm{M}$ and (F) $36 \mu \mathrm{M}$. Excitation was fixed at $520 \mathrm{~nm}$ and emission at $600 \mathrm{~nm}$. Data represent mean $\pm \operatorname{sem}(\mathrm{n}=3)$. Least square fit (line) gave the thermodynamic dissociation constant $K_{\mathrm{D}, \mathrm{Ca}}$ and Hill coefficient $n_{\mathrm{H}}$. 

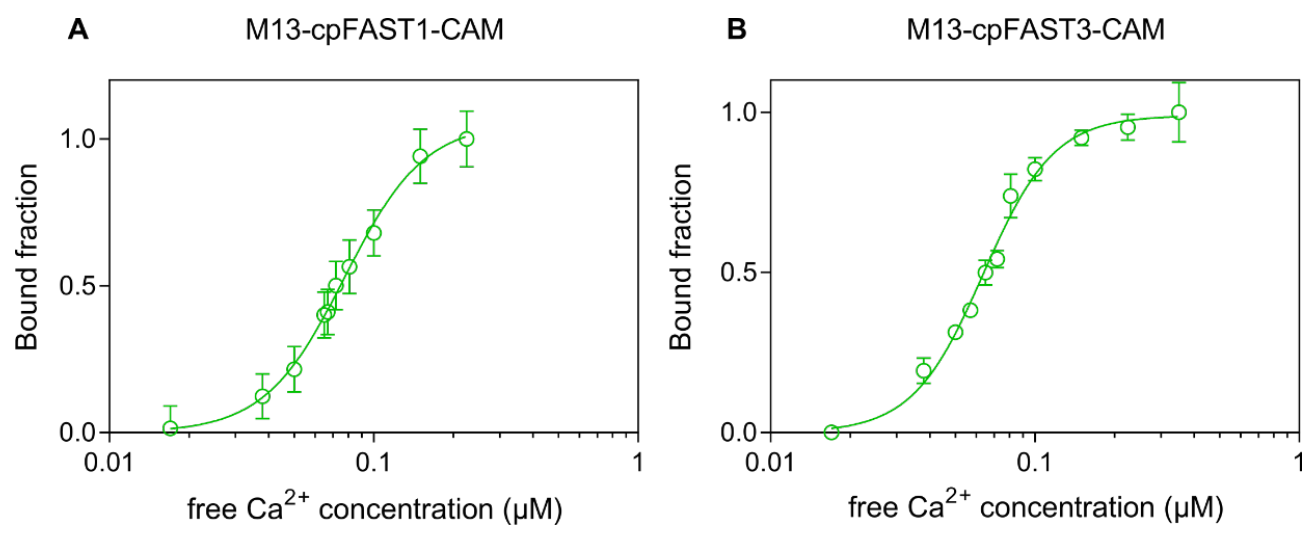

Figure S12. $\mathrm{Ca}^{2+}$ titration curves of M13-cpFAST-CaM in presence of HMBR. (A) M13-cpFAST1-CaM. (B) M13-cpFAST3-CaM. Titrations were done at a sensor concentration of $100 \mathrm{nM}$ and a HMBR concentration of $\left(K_{\mathrm{D},+} K_{D,-}\right)^{1 / 2}$ at $25^{\circ} \mathrm{C}$. Excitation was fixed at $480 \mathrm{~nm}$ and emission at $540 \mathrm{~nm}$. Data represent mean \pm sem $(\mathrm{n}=3)$. Least square fit (line) gave the thermodynamic dissociation constant $K_{\mathrm{D}, \mathrm{Ca}}$ and Hill coefficient $n_{H}$ provided in Table 2. 

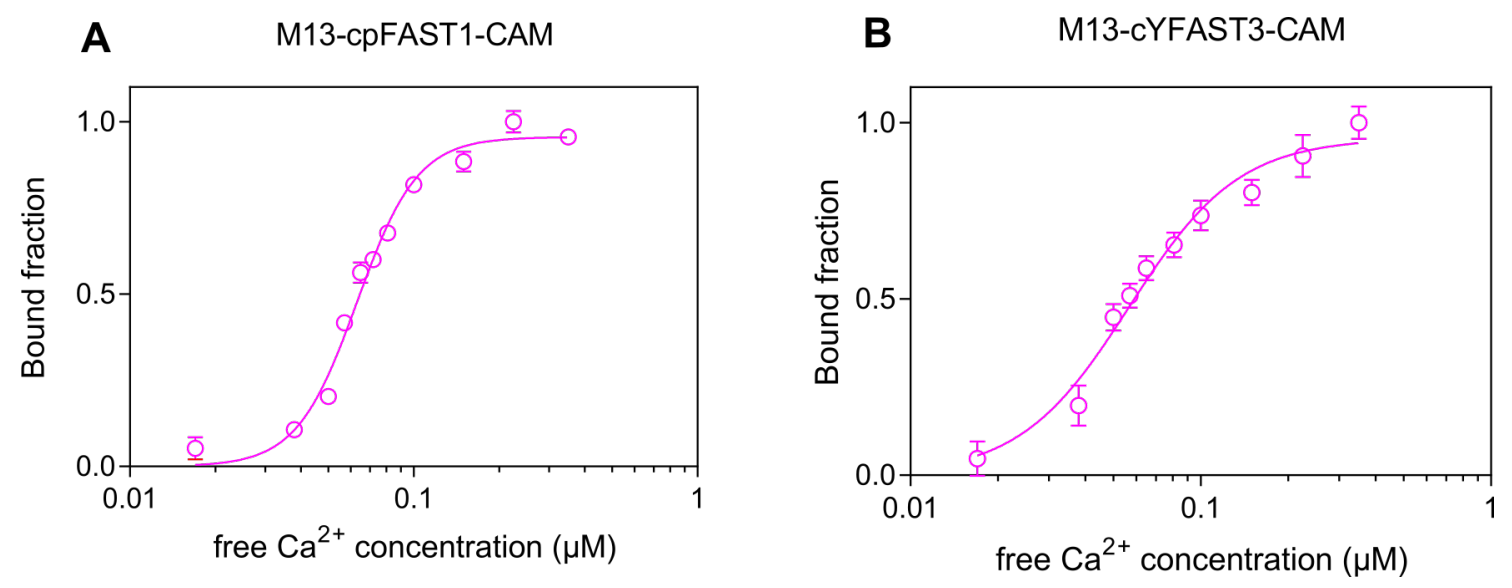

Figure S13. $\mathrm{Ca}^{2+}$ titration curves of M13-cpFAST-CaM in presence of HBR-3,5-DOM. (A) M13-cpFAST1-CaM. (B) M13-cpFAST3-CaM. Titrations were done at a sensor concentration of $100 \mathrm{nM}$ and a HBR-3,5-DOM concentration of $\left(K_{\mathrm{D},+} K_{D,-}\right)^{1 / 2}$ at $25{ }^{\circ} \mathrm{C}$. Excitation was fixed at $520 \mathrm{~nm}$ and emission at $600 \mathrm{~nm}$. Data represent mean $\pm \operatorname{sem}(\mathrm{n}$ $=3$ ). Least square fit (line) gave the thermodynamic dissociation constant $K_{\mathrm{D}, \mathrm{Ca}}$ and Hill coefficient $n_{\mathrm{H}}$ provided in Table 2. 


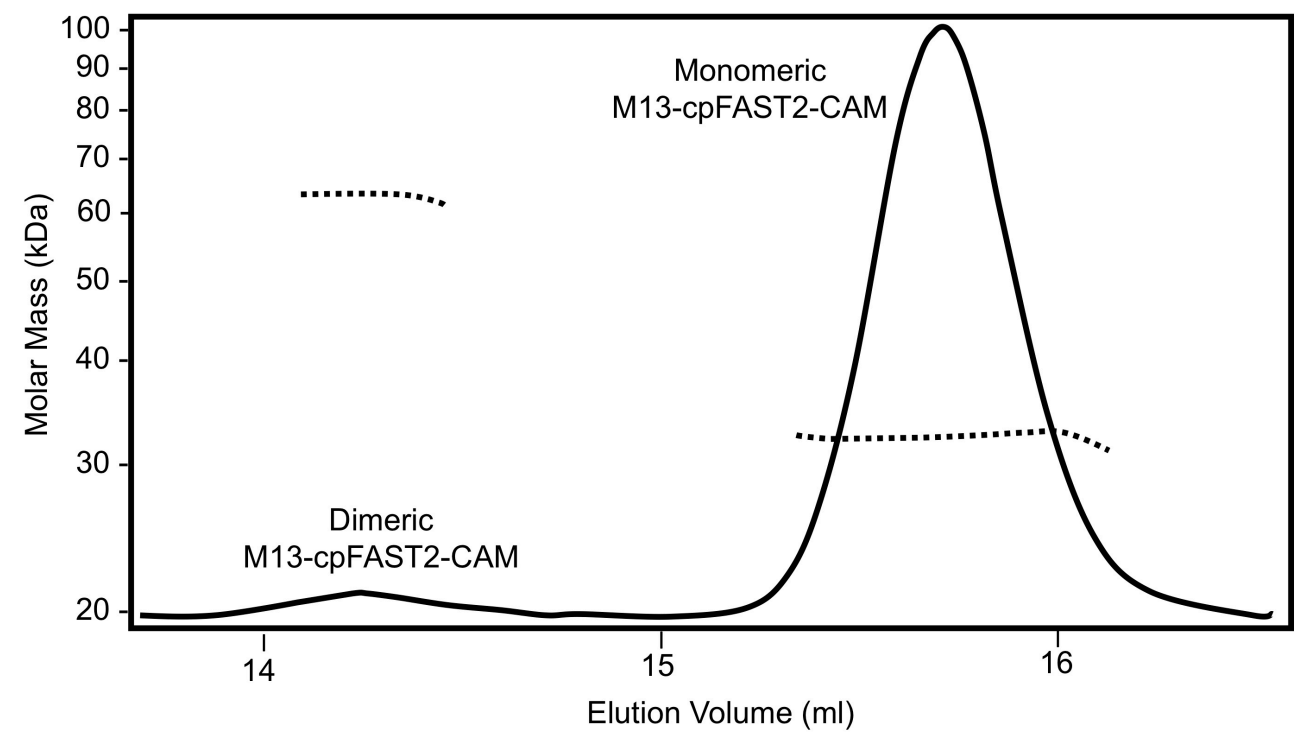

Figure S14. SEC-MALS analysis of recombinant M13-cpFAST2-CaM in $10 \mathrm{mM}$ HEPES, $50 \mathrm{mM} \mathrm{NaCl}, 2 \mathrm{mM} \mathrm{CaCl}$, pH 7.5. Continuous line: static light scattering, normalised from 3 angles; dotted line: molecular mass in $\mathrm{kDa}$. Concentration at the monomer peak was $\sim 5 \mathrm{mg} / \mathrm{ml}=161 \mu \mathrm{M}$. In the conditions used, $96 \%$ of M13-cpFAST2CaM (33.4 kDa) was monomeric and $4 \%$ was found to be dimeric. Note that no dimers were detected when the SEC column was equilibrated in buffer containing $1 \mathrm{mM}$ EGTA instead of $2 \mathrm{mM} \mathrm{CaCl}_{2}$ (i.e. in absence of $\mathrm{Ca}^{2+}$ ). 


\section{MATERIALS AND METHODS}

General FAST is a variant of the photoactive yellow protein (PYP) containing the mutations C69G, Y94W, T95M, F96I, D97P, Y98T, Q99S, M100R, T101G. HMBR and HBR-3,5-DOM were prepared as previously described ${ }^{1,2}$.

Molecular Biology The genes encoding the circularly permuted FAST variants were constructed by PCR assembly from the gene encoding FAST optimized for human codon usage $^{1}$. The plasmids for bacterial expression of cpFAST1-7 were generated by inserting the cpFAST1-7 DNA sequence in the plasmid pET18a using the Nhe I and Xho I restriction sites. The plasmids for mammalian expression of mcherry-cpFAST1-5 were constructed by replacing FAST DNA sequence by the cpFAST1-5 DNA sequence in pAG96 encoding mCherry-GGGS-FAST ${ }^{1}$. The calcium sensors were generated from a synthetic sequence (Eurofins) coding for M13-linker-CaM and inserted in the plasmid pET28a using Nhe I and Xho I. The sequence for M13 used was MVDSSRRKWNKTGHAVRAIGRLSS. The sequence for CaM was DQLTEEQIAEFKEAFSLFDKDGDGTITTKELGTVMRSLGQNPTEAELQDMINEVDADG DGTIDFPEFLTMMARKMNDTDSEEEIREAFRVFDKDGNGYIGAAELRHVMTNLGEKLT DEEVDEMIRVADIDGDGQVNYEEFVQMMTAK. The various cpFAST DNA sequences were amplified by PCR and inserted using Mfe I and Sac I restriction sites present in the linker between $\mathrm{M} 13$ and $\mathrm{CaM}$. The plasmids for mammalian expression of the circularly permuted FAST variants and the cpFAST-based calcium biosensors were generated by inserting the corresponding DNA sequences into the previously reported pAG104 plasmid ${ }^{1}$ using $B a m H I$ and $B g I I I$

Protein expression and purification Expression vectors were transformed in Rosetta (DE3) pLysS E. coli (New England Biolabs). Cells were grown at $37^{\circ} \mathrm{C}$ in Lysogeny Broth (LB) medium complemented with $50 \mu \mathrm{g} / \mathrm{ml}$ kanamycin and $34 \mu \mathrm{g} / \mathrm{ml}$ chloramphenicol to $\mathrm{OD}_{600 \mathrm{~nm}}$ 0.6. Expression was induced for $4 \mathrm{~h}$ by adding isopropyl $\beta-D-1-$ thiogalactopyranoside (IPTG) to a final concentration of $1 \mathrm{mM}$. Cells were harvested by centrifugation $\left(4,000 \times \mathrm{g}\right.$ for $20 \mathrm{~min}$ at $\left.4^{\circ} \mathrm{C}\right)$ and frozen. The cell pellet was resuspended in lysis buffer (phosphate buffer $50 \mathrm{mM}, \mathrm{NaCl} 150 \mathrm{mM}, \mathrm{MgCl}_{2} 2.5 \mathrm{mM}$, protease inhibitor, DNase, $\mathrm{pH} 7.4$ ) and sonicated (5 min at $20 \%$ of amplitude, $3 \mathrm{sec}$ on, $1 \mathrm{sec}$ off). The 
lysate was incubated for $2 \mathrm{~h}$ at $4{ }^{\circ} \mathrm{C}$ to allow DNA digestion by DNase. Cellular fragments were removed by centrifugation $\left(9200 \times \mathrm{g}\right.$ for $1 \mathrm{~h}$ at $\left.4^{\circ} \mathrm{C}\right)$. The supernatant was incubated overnight at $4^{\circ} \mathrm{C}$ under gentle agitation with Ni-NTA agarose beads in phosphate buffered saline (PBS) (sodium phosphate $50 \mathrm{mM}, \mathrm{NaCl} 150 \mathrm{mM}, \mathrm{pH}$ 7.4) complemented with 10 $\mathrm{mM}$ imidazole. Beads were washed with 20 volumes of PBS containing $20 \mathrm{mM}$ Imidazole, and with 5 volumes of PBS complemented with $40 \mathrm{mM}$ Imidazole. His-tagged proteins were eluted with 5 volumes of PBS complemented with $0.5 \mathrm{M}$ Imidazole. The buffer was exchanged to PBS (50 mM phosphate, $150 \mathrm{mM} \mathrm{NaCl}, \mathrm{pH}$ 7.4) for cpFAST or HEPES buffer (HEPES $50 \mathrm{mM}, \mathrm{NaCl} 259 \mathrm{mM}, \mathrm{pH}$ 7.4) for calcium sensors using PD-10 desalting columns.

Instrumentation Steady state UV-Vis absorption spectra were recorded using a Cary 300 UV-Vis spectrometer (Agilent Technologies), equipped with a Versa20 Peltier-based temperature-controlled cuvette chamber (Quantum Northwest) and fluorescence data were recorded using a LPS 220 spectrofluorometer (PTI, Monmouth Junction, NJ), equipped with a TLC50TM Legacy/PTI Peltier-based temperature-controlled cuvette chamber (Quantum Northwest). Thermodynamic dissociation constants were determined with a Spark 10M plate reader (Tecan).

Thermodynamic analysis The thermodynamic dissociation constants $K_{\mathrm{D},+}$ and $K_{\mathrm{D},-}$ were determined in HEPES buffer (HEPES $50 \mathrm{mM}, \mathrm{NaCl} 259 \mathrm{mM}, \mathrm{pH} 7.4$ ) containing either 10 $\mathrm{mM} \mathrm{CaCl}_{2}$ or $10 \mathrm{mM} \mathrm{EGTA}$, while the $\mathrm{pH}$ in solution was kept constant at 7.4. Normalized fluorescence (or bound fraction) were plotted as a function of fluorogen concentration and fitted using one site specific binding equation to provide $K_{\mathrm{D},+}$ and $K_{\mathrm{D},-.}$. The thermodynamic dissociation constants $K_{\mathrm{D}, \mathrm{Ca}}$ were determined using buffers with precise free $\mathrm{Ca}^{2+}$ concentration either purchased commercially (ThermoFisher) or prepared following protocols previously reported by Roger Tsien et al. ${ }^{3}$ by reciprocal dilution of a $\mathrm{Ca}^{2+}$ saturated solution (10 mM CaEGTA in HEPES buffer) and a $\mathrm{Ca}^{2+}$ free solution (10 mM $\mathrm{K}_{2}$ EGTA in HEPES buffer) to give a series of solutions with free $\mathrm{Ca}^{2+}$ concentration ranging from 0 to $0.351 \mu \mathrm{M}$ at $\mathrm{pH}$ 7.2. In these experiments, the fluorogen concentration was fixed at the optimal fluorogen concentration $\left(K_{D,+} K_{D,-}\right)^{1 / 2}$. The normalized 
fluorescence intensity of the calcium sensors was plotted as a function of $\mathrm{Ca}^{2+}$ concentration and fitted to the Hill equation used for cooperative ligand-receptor binding.

\section{Size Exclusion Chromatography - Multi-Angle Light Scattering (SEC-MALS)} Purified M13-cpFAST2-CaM (3.5 mg at $113 \mu \mathrm{M}$ ) was injected in a Superdex 200 Increase (GE Lifesciences) previously equilibrated in $10 \mathrm{mM} \mathrm{HEPES,} 50 \mathrm{mM} \mathrm{NaCl}, 2 \mathrm{mM} \mathrm{CaCl}$, $\mathrm{pH} 7.5$ connected to a TREOS static light detector and to a t-Rex refractometer (both purchased from Wyatt Technologies). Molecular mass was determined by the Astra software (Wyatt).

Mammalian cell culture HeLa cells were cultured in Dulbecco's Modified Eagle Medium (DMEM) supplemented with phenol red, Glutamax I, and 10\% (vol/vol) fetal calf serum (FCS), at $37^{\circ} \mathrm{C}$ in a $5 \% \mathrm{CO}_{2}$ atmosphere. For imaging, cells were seeded in $\mu$ Dish IBIDI (Biovalley) coated with poly-L-lysine. Cells were transiently transfected using Genejuice (Merck) according to the manufacturer's protocol for 24 hours prior to imaging.

Fluorescence microscopy Confocal micrographs were acquired on a Zeiss LSM 710 Laser Scanning Microscope equipped with a Plan Apochromat 63×/1.4 NA oil immersion objective. For calcium imaging, cells were washed twice with Dulbecco's PhosphateBuffered Saline (DPBS) immediately prior to imaging. After rinsing, solution of fluorogen in HHBSS (20 mM HEPES buffered Hanks balanced salt solution (HBSS) containing 2 g/L D-glucose) were added to the cells. Histamine-induced $\mathrm{Ca}^{2+}$ dynamics were imaged at intervals of $250 \mathrm{~ms}$ for $15-20 \mathrm{~min}$. Approximately $2 \mathrm{~min}$ after the start of the experiment, histamine (50 $\mu \mathrm{M}$ final concentration) in HHBSS containing the appropriate amount of fluorogen to maintain it constant was added to allow histamine-induced oscillations to subside. ZEN software was used to collect the data. Raw images were analyzed with Image $\mathrm{J}$ using a line $\mathrm{ROI}$ with a width of 15 pixels. Presented images are a maximum projection of 10 raw images while the movies were generated as a walking average of 5 frames. 


\section{SI References}

(1) Plamont, M.-A., Billon-Denis, E., Maurin, S., Gauron, C., Pimenta, F. M., Specht, C. G., Shi, J., Querard, J., Pan, B., Rossignol, J., Moncoq, K., Morellet, N., Volovitch, M., Lescop, E., Chen, Y., Triller, A., Vriz, S., Le Saux, T., Jullien, L., and Gautier, A. (2016) Small fluorescence-activating and absorption-shifting tag for tunable protein imaging in vivo. Proc Natl Acad Sci USA 113, 497-502.

(2) Li, C., Plamont, M.-A., Sladitschek, H. L., Rodrigues, V., Aujard, I., Neveu, P., Le Saux, T., Jullien, L., and Gautier, A. (2017) Dynamic multicolor protein labeling in living cells. Chem Sci 8, 5598-5605.

(3) Tsien, R., and Pozzan, T. (1989) Measurement of cytosolic free $\mathrm{Ca}^{2+}$ with quin2. Methods in Enzymology, pp 230-262. Elsevier. 